\title{
Impairment of human neural crest cell migration by prolonged exposure to interferon-beta
}

\author{
Giorgia Pallocca ${ }^{1}\left(\right.$ Johanna Nyffeler $^{1} \cdot$ Xenia Dolde $^{1} \cdot$ Marianna Grinberg $^{2} \cdot$ \\ Gerhard Gstraunthaler $^{3}$. Tanja Waldmann ${ }^{1} \cdot$ Jörg Rahnenführer $^{2}$. \\ Agapios Sachinidis $^{4} \cdot$ Marcel Leist $^{1}$
}

Received: 6 February 2017 / Accepted: 21 March 2017 / Published online: 1 April 2017

(c) The Author(s) 2017. This article is an open access publication

\begin{abstract}
Human cell-based toxicological assays have been used successfully to detect known toxicants, and to distinguish them from negative controls. However, there is at present little experience on how to deal with hits from screens of compounds with yet unknown hazard. As a case study to this issue, we characterized human interferon-beta (IFN $\beta$ ) as potential developmental toxicant affecting neural crest cells (NCC). The protein was identified as a hit during a screen of clinically used drugs in the 'migration inhibition of neural crest' (MINC) assay. Concentration-response studies in the MINC combined with immunocytochemistry and mRNA quantification of cellular markers showed that IFN $\beta$ inhibited NCC migration at concentrations as low as $20 \mathrm{pM}$. The effective concentrations found here correspond to levels found in human plasma, and they were neither cytostatic nor cytotoxic nor did they did they affect the differentiation state and overall phenotype of NCC. Data from two other migration assays confirmed that picomolar concentration of IFN $\beta$ reduced the motility of NCC, while
\end{abstract}

Electronic supplementary material The online version of this article (doi:10.1007/s00204-017-1966-1) contains supplementary material, which is available to authorized users.

Giorgia Pallocca

giorgia.pallocca@uni-konstanz.de

1 Department of In Vitro Toxicology and Biomedicine, University of Konstanz, Box 657, 78457 Konstanz, Germany

2 Department of Statistics, TU Dortmund, 44139 Dortmund, Germany

3 Department of Physiology, University of Innsbruck, 6020 Innsbruck, Austria

4 Center of Physiology and Pathophysiology, Institute of Neurophysiology, University of Cologne, 50931 Cologne, Germany other interferons were less potent. The activation of JAK kinase by IFN $\beta$, as suggested by bioinformatics analysis of the transcriptome changes, was confirmed by biochemical methods. The degree and duration of pathway activation correlated with the extent of migration inhibition, and pharmacological block of this signaling pathway before, or up to $6 \mathrm{~h}$ after exposure to the cytokine prevented the effects of IFN $\beta$ on migration. Thus, the reduction of vital functions of human NCC is a hitherto unknown potential hazard of endogenous or pharmacologically applied interferons.

Keywords Interferons - Neural crest - Cell migration · JAK-STAT pathway $\cdot$ Developmental toxicity

$\begin{array}{ll}\text { Abbreviations } \\ \text { AKT } & \text { Protein kinase B } \\ \text { AraC } & \text { Cytosine arabinoside } \\ \text { CM } & \text { Cytokine mix } \\ \text { TNF } \alpha & \text { Tumor necrosis factor } \alpha \\ \text { DEG } & \text { Differentially expressed genes } \\ \text { EdU } & \text { 5-Ethynyl-deoxyuridine } \\ \text { ERK } & \text { Extracellular signal regulated kinase } \\ \text { ESNATS } & \text { Embryonic stem cell-based novel alternative } \\ & \text { testing strategies } \\ \text { FAK } & \text { Focal adhesion kinase } \\ \text { FC } & \text { Fold change } \\ \text { FDA } & \text { Food and drugs administration } \\ \text { FDR } & \text { False discovery rate } \\ \text { GFP } & \text { Green fluorescent protein } \\ \text { GO } & \text { Gene ontology } \\ \text { EC } & \text { Effective concentration } \\ \text { GSK3 } \beta & \text { Glycogen synthase kinase } 3 \beta \\ \text { hESC } & \text { Human embryonic stem cell } \\ \text { IFI } & \text { Interferon inducible protein } \\ \text { IFN } & \text { Interferon }\end{array}$




$\begin{array}{ll}\text { IFNAR } & \text { Interferon alpha and beta receptor } \\ \text { IL-1 } \beta & \text { Interleukin } 1 \beta \\ \text { IRF } & \text { Interferon regulatory factor } \\ \text { ISG } & \text { Interferon stimulated gene } \\ \text { ISGF } & \text { Interferon stimulated gene factor } \\ \text { JAK } & \text { Janus kinase } \\ \text { LOAEL } & \text { Lowest observed adverse effect level } \\ \text { MINC } & \text { Migration inhibition of neural crest } \\ \text { MIU } & \text { Million international units } \\ \text { MS } & \text { Multiple sclerosis } \\ \text { MTE } & \text { Mesenchymal-to-epithelial } \\ \text { NC } & \text { Neural crest } \\ \text { NCC } & \text { Neural crest cell } \\ \text { PCA } & \text { Principal component analysis } \\ \text { PS } & \text { Probe set } \\ \text { STAT } & \text { Signal transducer and activator of transcription } \\ \text { TSA } & \text { Trichostatin A } \\ \text { VPA } & \text { Valproic acid }\end{array}$

\section{Introduction}

Any kind of external interference which alters the spatiotemporal organization of development can lead to developmental defects (Smirnova et al. 2014; Aschner et al. 2017). Where protein signals are involved in the fine-tuning of cell and organ development, antigenic properties and receptor affinities play an important role. As these factors are often species-specific, the developmental hazard, and many other side effects of cytokines, antibodies and blood factors are difficult to assess in animal models. As alternative approach, human cell-based test systems have been developed and they play an increasingly important role in drug development.

The approach of using in vitro tests is based on the strategy that a battery of assays may be assembled that covers the majority of fundamental developmental processes (Leist et al. 2014; Smirnova et al. 2014; Schmidt et al. 2016). These include, for instance, neural differentiation (Zimmer et al. 2011b; Balmer et al. 2012), neurite outgrowth (Stiegler et al. 2011; Krug et al. 2013a), gliogenesis (Fritsche et al. 2005; Kleiderman et al. 2016), myelination (Zurich et al. 2000, 2002), or synaptogenesis (Harrill et al. 2011).

In this context, the migration inhibition of neural crest cells (MINC) assay was developed as the first method to test effects of toxicants on the function of the neural crest (NC) during development (Zimmer et al. 2012; Dreser et al. 2015). The importance of this developmental stage justified the inclusion of the MINC assay in the in vitro test battery of the European research consortium ESNATS (Embryonic Stem cell-based Novel Alternative Testing Strategies) (Zimmer et al. 2014). The NC is a multipotent migratory cell population that emerges from the dorsal aspect of the neural tube in the early phases of development. NC cells (NCC) are capable of long range migration, which is finely regulated in the embryo. During migration, and at the final destination, $\mathrm{NCC}$ give rise to a multitude of different cell types, supporting the formation of cartilage and bone of the face, but also peripheral and enteric neurons, melanocytes, and some cardiomyocytes (Huang and Saint-Jeannet 2004).

A large percentage of developmental disorders (e.g., congenital heart defects, oro-facial clefts, and Hirschsprung's disease) are caused by NCC deficits (Simões-Costa and Bronner 2013), and these often correlate with neural tube defects. Such alterations can be induced by genetic factors (Lee et al. 2009) or exposure to pharmaceuticals (e.g., valproic acid) (Fuller et al. 2002) and pesticides (e.g., triadimefon) (Menegola et al. 2000).

The MINC assay has been used to screen and evaluate the effects of many different compounds on neural crest function (Zimmer et al. 2012, 2014; Dreser et al. 2015). In addition to known environmental toxicants, the screening identified some drug-like compounds as hits, and these included the type I interferon IFN $\beta$ (Zimmer et al. 2014). The developmental toxicity of IFN $\beta$ has been evaluated in cynomolgus monkeys, where an increased incidence of both abortions and stillbirths was observed (FDA 1999). Furthermore, epidemiological studies indicated that exposure to IFN $\beta$ in pregnancy is associated with lower mean birth weight, and preterm birth (Amato et al. 2010). For these reasons, women with MS are typically advised to discontinue the treatment before conceiving. IFN $\beta$ is classified as risk class $\mathrm{C}$ drug by the FDA, indicating that "animal reproduction studies have shown an adverse effect on the fetus and there are no adequate and well-controlled studies in humans, but potential benefits may warrant the use of the drug in pregnant women despite the potential risks" ( $\mathrm{Lu}$ et al. 2012; Pozzilli and Pugliatti 2015).

The interferon family is clinically used for different purposes, as interferons have a crucial role in the anti-viral cell response, and in modulating several functions of the immune system. Type I interferons comprise IFN $\alpha$ and IFN $\beta$. All type I IFNs bind the interferon alpha and beta receptor (IFNAR) subunits and produce structurally highly similar receptor-ligand complexes (Schreiber and Piehler 2015). While IFN $\alpha$ is mainly used for treatment of certain types of leukemia and hepatitis virus infections, the immunomodulatory drug IFN $\beta$ has proven effective in the treatment of relapsing-remitting multiple sclerosis (MS) (Dhib-Jalbut and Marks 2010). The mode of action of the latter cytokine is still not fully understood, but it induces an anti-inflammatory cytokine shift and prevents T-cell adhesion and extravasation across the blood-brain barrier. The type II interferon IFN $\gamma$ binds to different receptors and has 
pronounced inflammatory and immune-stimulating properties (Schroder et al. 2004).

While elaborate strategies have been established for hit follow-up of drug discovery screens, such concepts still need to be developed for toxicological high-throughput testing. For statistical, strategic, and technical reasons, large screens have a high propensity to yield false-positives. Two approaches have proven useful in drug discovery: (1) follow-up of screen results under non-screen conditions (new compounds, new cells, low throughput, and low time constraint to allow stringent controls of each step), first with the original assay, then with secondary and tertiary tests; (2) exploration around the hit findings (use of related compounds; exploration of mechanistic and temporal consistency) to provide biological plausibility and a more robust data base. Such a strategy was explored in the present study to further substantiate or refute a potential developmental toxicity hazard of IFN $\beta$. The adverse effects of IFN $\beta$ on NCC migration and proliferation were studied in three different assays. Additional analysis of transcriptome changes was performed, and the JAK-STAT signaling pathway was considered as a mediator of toxicity. The role of the pathway in a potential hazard of IFN $\beta$ was confirmed by detailed measurements of interferon effects on signaling and cell function in the presence of specific kinase inhibitors.

\section{Materials and methods}

\section{Cell culture and neural crest differentiation}

The reporter human embryonic stem cell line H9-Dll1 (GFP under Dll1 promoter) was provided by Mark Tomishima from the Memorial Sloan Kettering Cancer Centre (MSKCC, NY, USA). Import of the cells and all experiments was carried out according to German legislation under the license number 1710-79-1-4-27 of the RobertKoch Institute.

H9-Dll1 cells were maintained on mouse embryonic fibroblasts in DMEM/F12 (Gibco ${ }^{\mathrm{TM}}$, Carlsbad, CA, USA) medium containing $20 \%$ of serum replacement (Knockout SR, Gibco ${ }^{\mathrm{TM}}$ ), HEPES (Gibco ${ }^{\mathrm{TM}}$ ), L-gluthamine (Glutamax, Gibco ${ }^{\mathrm{TM}}$ ), non-essential amino acids (MEM NEAA, Gibco $\left.^{\mathrm{TM}}\right)$, beta-mercaptoethanol $\left(\mathrm{Gibco}^{\mathrm{TM}}\right)$, and basic fibroblast growth factor $\left(10 \mathrm{ng} / \mathrm{ml}\right.$, Invitrogen ${ }^{\mathrm{TM}}$, Carlsbad, CA, USA).

Differentiation of hESC into NCC was initiated on mitomycin C (Sigma-Aldrich $\odot$, St. Louis, MO, USA) treated murine bone-marrow derived stromal MS5 cells and continued in N2 medium exactly as described previously (Zimmer et al. 2012).
The human breast adenocarcinoma cell line MDAMB-231 (ATCC HTB-26 ${ }^{\mathrm{TM}}$ ) was maintained in DMEM Glutamax $\left(\mathrm{Gibco}^{\mathrm{TM}}\right)$ containing 10\% FCS (Invitrogen) and $1 \%$ penicillin/streptomycin.

\section{Cell culture quality control}

Cell culture experiments were performed according to GCCP (good cell culture practice) principles. All cell lines were regularly tested for mycoplasma contamination by the use of commercial kits (Venor Gem, Minerva Biolabs).

Identity of the used cell types was confirmed by STR (Short Tandem Repeat) analysis. Briefly, DNA samples from the H9 (NIH registry name WA09) and H9-Dll1 cell lines were prepared using a commercial kit (Puregene Cell Kit, Qiagen). The kit GlobalFiler ${ }^{\circledR}$ PCR Amplification Kit (Thermofisher) was then used to determine the cell-specific profile for 16 different genomic loci using an Applied Biosystems GeneMapper Device. STR results showed $100 \%$ identity of the profiles of H9 and H9-Dll1, and these matched $100 \%$ the literature reference data (Josephson et al. 2006) (suppl. Fig S1).

\section{Interferon exposure during NCC migration}

NCC were exposed for $48 \mathrm{~h}$ to non-cytotoxic concentration of different interferons (recombinant human IFNbeta $1 \mathrm{a}$, recombinant human IFN-alpha $2 \mathrm{a}$, recombinant human IFN-gamma) in N2 medium containing human EGF (20 ng/ml) and FGF2 (20 ng/ml) (all from R\&D Systems $\mathrm{GmbH}^{\circledR}$, Minneapolis, MN, USA). Interferon stock solutions were prepared in $0.1 \%$ BSA in PBS at concentrations of $200 \mathrm{nM}$ and $10 \mu \mathrm{M}$, respectively, for IFN-beta 1a and IFN-alpha 2a. We assumed the nominal drug concentrations indicated in the figures/tables to correspond closely to the actual free concentrations, as protein binding of IFN $\beta$ is low $(<10 \%)$. However, some absorption to the cell culture plastic might have occurred. Where indicated, cytosine arabinoside (AraC, Sigma) or JAK inhibitors (Ruxolitinib and Tofacitinib, Selleckchem $\odot$, Munich, Germany) were added. The migration assay was performed as described previously (Nyffeler et al. 2016). Briefly, NCC cells were seeded $\left(95,000\right.$ cells $\left./ \mathrm{cm}^{2}\right)$ in 96 -well plates (Corning $\odot$, NY, USA) previously coated with $10 \mu \mathrm{g} / \mathrm{ml}$ poly-L-ornithine in $100 \mu \mathrm{l}$ phosphate buffered saline (PBS) (GE Healthcare Bio-Sciences $\odot$, Pittsburgh, PA, USA) and $1 \mu \mathrm{g} / \mathrm{ml}$ fibronectin and $1 \mu \mathrm{g} / \mathrm{ml}$ laminin (Sigma-Aldrich) in $100 \mu \mathrm{l}$ PBS. Cells were seeded in the presence of silicon stoppers (Platypus Technologies, Madison, WI, USA) to create a circular cell-free area. One day after seeding, migration into the cell-free area was initiated by manual removal of the stoppers and the medium was replaced with medium containing the test compounds. After $48 \mathrm{~h}$, NCC were 
stained with $1 \mu \mathrm{g} / \mathrm{ml} \mathrm{H}-33342$ (nuclei) and $533 \mathrm{nM}$ calceinAM (to stain the outline of viable cells) (Sigma-Aldrich) and imaged 30 min later on a high content imaging microscope (Cellomics ArrayScanVTI, Thermo Fischer@), Boston, MA, USA).

Viability was defined as the number of H-33342 and calcein double-positive cells, as determined by an automated algorithm described earlier (Stiegler et al. 2011; Krug et al. 2013b). For quantification of migration, a software tool (freely accessible at http://invitrotox.uni-konstanz.de/) was developed to estimate the most likely position of the previously cell-free area (covered by the silicon stopper), to set thresholds for color intensity for both dyes, and to count the number of H-33342 and calcein double-positive cells in the region of interest.

\section{EdU staining}

Cells were treated for $48 \mathrm{~h}$ with $10 \mu \mathrm{M}$ 5-ethynyl-deoxyuridine (EdU). Proliferating cells incorporate EdU and can be detected using a click reaction procedure, as described in the manufacturer's protocol (EdU-Click 555, PanaTecs, Heilbronn, Germany). Images were acquired using a high content imaging microscope (Cell Insight Personal Imager, Thermo Fisher(C). Proliferation was defined as the percentage of EdU-positive nuclei among all H-33342 positive nuclei.

\section{Immunofluorescence staining}

Cells were seeded in Lumox ${ }^{\circledR}$ multiwell plates $(95,000$ cells $/ \mathrm{cm}^{2}$ ). After 42-h treatment, the middle of the well was scratched with a pipette tip to create a cell-free space in the well and cells were allowed to migrate for $6 \mathrm{~h}$ in presence of the treatment. Finally, the cells were fixed in 4\% PFA for immunofluorescence staining. Cells were permeabilized for $10 \mathrm{~min}$ in $0.2 \%$ Triton and blocked with $10 \%$ FBS for $1 \mathrm{~h}$. Afterwards, cells were incubated overnight with primary antibody (GM130, Abcam $\odot$, Cambridge, UK; TOM20, Santa Cruz Biotechnology ${ }^{\mathrm{TM}}$, Santa Cruz, CA, USA) or Alexa Fluor 555 phalloidin diluted in 4\% FBS. After a washing step, the secondary antibody was applied for $1 \mathrm{~h}$. Cell nuclei were finally stained with H-33342. Images were acquired mainly from the scratch area (to capture migrating cells at a density typically also found in the standard cMINC assay setup) using a point laser scanning confocal microscope Zeiss LSM 700 (Zeiss@, Oberkochen, Germany).

\section{Western blot}

Cells were seeded in 6-well plates $\left(50,000\right.$ cells $\left./ \mathrm{cm}^{2}\right)$; after $24 \mathrm{~h}$, cells were treated for the indicated times. Cells were then harvested in Laemmli buffer, boiled for $5 \mathrm{~min}$ at $95^{\circ} \mathrm{C}$ and purified with the NucleoSpin Filters (Macherey-Nagel GmbH, Düren, Germany). Samples were run on SDS-PAGE. Transfer on nitrocellulose membranes was performed by using iBlot ${ }^{\mathrm{TM}} 2$ Dry Blotting System (Invitrogen). Membranes were then incubated in 5\% milk in T-TBS for $1 \mathrm{~h}$ and overnight with the primary antibody in 5\% BSA in T-TBS at $4{ }^{\circ} \mathrm{C}$ (p-STAT1 Y701, Cell signaling technology). After washing steps, membranes were incubated with secondary antibody conjugated with horseradish peroxidase (GE Healthcare Bio-Sciences $\odot$ ) for $1 \mathrm{~h}$ at room temperature. Signal was finally detected using Pierce ECL wester blotting substrate (Thermo Scientific $\odot$ Boston, MA, USA) and imaged with a Fusion-SL $3500 \mathrm{WL}$ device and Fusion software (Bio-Rad ${ }^{\mathrm{TM}}$, Hercules, CA, USA). Afterwards, the membrane was further incubated for $3 \mathrm{~h}$ with the primary antibody specific for the housekeeping protein GAPDH (Invitrogen). The same procedure as described above was followed for detection and imaging of the housekeeping signal.

\section{NFkB translocation}

Cells were stimulated by a cytokine mix (CM) containing $10 \mathrm{ng} / \mathrm{ml}$ tumor necrosis factor $\alpha(\mathrm{TNF} \alpha), 10 \mathrm{ng} / \mathrm{ml}$ interleukin $1 \beta$ (IL-1 $\beta$ ), and $20 \mathrm{ng} / \mathrm{mL}$ IFN $\gamma$ (R\&D Systems, Wiesbaden, Germany) or with $500 \mathrm{pM}$ IFN $\beta$ for $1 \mathrm{~h}$. For NFkB measurement, cells were fixed, permeabilized, and stained with NFkB antibody (Santa Cruz Biotechnology $^{\mathrm{TM}}$ ). NFkB translocation was measured with the highthroughput device CellInsight TM CX5 High Content Screening (Thermo Scientific()) using the nuclear translocation algorithm as described previously (Henn et al. 2011).

\section{Cell tracking}

Live cell imaging was performed using an Axio Observer. Z1 microscope (Zeiss $\odot$ ) equipped with an incubation system $\left(37^{\circ} \mathrm{C}, 5 \% \mathrm{CO}_{2}\right)$ and the software Zen2. Cells were imaged for a period of $48 \mathrm{~h}$, taking phase contrast pictures every 15 min with a $5 x$ objective. Images of the last $30 \mathrm{~h}$ migration period were loaded in Fiji ImageJ and manually tracked with the plugin "Manual track" Schindelin et al. (2012). The tracked positions were then loaded into the freely available "Chemotaxis and Migration Tool" (Ibidi) to calculate the total distance and the cell speed as well as to create the track pictures.

\section{Transwell assay}

Cells were treated for $42 \mathrm{~h}$ and then detached by using Accutase (Corning@), counted and seeded (50,000 cells/ 
transwell) in upper chamber of previously coated Transwell Permeable Support plates $(0.8 \mu \mathrm{m}$ polycarbonate membrane, Costar, Corning( ()) in normal medium with addition of IFN $\beta(500 \mathrm{pM})$ or respective control. Ten percent FBS in normal medium was added in the lower chamber of the transwell. After $6 \mathrm{~h}$ of incubation at $37^{\circ} \mathrm{C}$, cells at the upper side of the membrane were removed and the cells attached to the lower side of the membrane were fixed and stained with crystal violet for $30 \mathrm{~min}$, and then washed in current water and let dry. Cells were imaged with light microscope Axio Observer.Z1 microscope (Zeiss $\odot$ ) using the software PALM RoboSoftware (4 fields per condition, $20 \times$ magnification) and manually counted in ImageJ.

\section{Affymetrix gene chip analysis}

Samples of $\geq 5 \times 10^{6}$ cells were collected using RNA protect reagent from Qiagen. The RNA was quantified using a NanoDrop N-1000 spectrophotometer (NanoDrop, Wilmington, DE, USA), and the integrity of RNA was confirmed with a standard sense automated gel electrophoresis system (Experion, Bio-Rad ${ }^{\mathrm{TM}}$, Hercules, CA, USA). Analysis was then performed as described earlier (Krug et al. 2013b) using Affymetrix chip-based DNA microarray (Human genome U133 plus 2.0 arrays) with all standard quality control procedures. The raw CEL files and secondary Affymetrix chip data have been deposited in the GEO database according to the MIME rules, with the accession number GSE94521. The differentially expressed probe sets for each compound including fold changes and $p$ values of the limma $t$ test are given in supplementary tables provided in an Excel file format (supplemental Table 1; Fig S3).

\section{Biostatistics}

The microarray data analysis (extrapolation and normalization of the array sets) was performed using the statistical programming language $\mathrm{R}$ (version 3.1.1) as described previously (Waldmann et al. 2014). For the normalization of the entire set of Affymetrix gene expression arrays, the Extrapolation Strategy (RMA+) algorithm (Harbron et al. 2007) was used that applies background correction, $\log _{2}$ transformation, quantile normalization, and a linear model fit to the normalized data to obtain a value for each probe set (PS) on each array. As reference, the normalization parameters obtained in earlier analyzes (Krug et al. 2013b) were used. After normalization, the difference between gene expression and corresponding controls was calculated (paired design). Differential expression was calculated using the R package 'limma' (Smyth et al. 2005). Here, the combined information of the complete set of genes is used by an empirical Bayes adjustment of the variance estimates of single genes. This form of a moderated $t$ test is abbreviated here as 'Limma $t$ test'. The resulting $p$ values were multiplicity-adjusted to control the false discovery rate (FDR) by the Benjamini-Hochberg procedure (Benjamini 1995). As a result, for each compound, a gene list was obtained, with corresponding estimates for log-fold changes and $p$ values of the Limma t test (unadjusted and FDR adjusted).

Transcripts with FDR adjusted $p$ values of $\leq 0.05$ and fold change values of $\geq 1.8$ or $\leq 0.55$ were considered significantly deregulated and defined as differential expressed genes (DEG).

\section{Data display: heat map and principal component analysis}

The software $\mathrm{R}$ (version 3.1.1), was used for all calculations and display of principal component analysis (PCA) and heatmaps. PCA plots were used to visualize expression data in two dimensions, representing the first two principal components. The percentages of the variances covered are indicated in the figures.

\section{Gene ontology (GO) and KEGG pathway enrichment analysis}

The gene ontology group enrichment was performed using $\mathrm{R}$ (version 3.1.1) with the topGO package (Alexa et al. 2006) using Fisher's exact test, and only results from the biological process ontology were kept. Here, again, the resulting $p$ values were corrected for multiple testing by the method of Benjamini-Hochberg (Benjamini 1995).

The KEGG pathway analysis was performed using the $\mathrm{R}$ package "hgu133plus2.db" (Carlson 2015). Probesets were mapped to the identifiers used by KEGG for pathways in which the genes represented by the probesets are involved. The enrichment was then performed analogous to the gene ontology group enrichment using Fisher's exact test.

Up- and down-regulated differentially expressed genes were analyzed separately for each treatment. Only GO classes and KEGG pathways with a BH (Benjamini-Hochberg)-adj. $p$ values $\leq 0.05$ were considered significant.

\section{GO superordinate classes distribution}

Enriched GOs were then assigned to superordinate cell biological processes as already described previously (Waldmann et al. 2014) and distributed in six classes: migration/ adhesion, metabolism, differentiation, signaling, stress response, and others. The migration class includes migration and adhesion-related-GO classes; stress response class includes cell death-, extracellular stressor-, and inflammation/immunity-related GO classes; signaling class consists 
of cell receptor activity-, second messenger (cAMP, cGMP, $\mathrm{Ca} 2+)$ metabolism-, and kinase modification-related GO classes. Metabolism class comprises all GO classes covering metabolism activity; differentiation class includes cell differentiation related- GO classes; and; "other" class covers the others not otherwise classified GO classes.

\section{Quantitative PCR (qPCR) analysis}

Cells were seeded in 6-well plates $\left(50,000\right.$ cells $\left./ \mathrm{cm}^{2}\right)$; after $24 \mathrm{~h}$, cells were treated for $48 \mathrm{~h}$. Cells were then harvested and lysed in PeqGOLD Trifast ${ }^{\mathrm{TM}}$ (PEQlab@, Erlangen, Germany). Total RNA was isolated by phenol-chloroform extraction. Reverse transcription was performed using $1 \mu \mathrm{g}$ RNA and the i-Script ${ }^{\mathrm{TM}}$ Reverse Transcription Supermix (Bio-Rad ${ }^{\mathrm{TM}}$ ) according to the manufacturer's protocol. Quantitative real-time PCR was performed with SsoFast EvaGreen Supermix (Bio-Rad ${ }^{\mathrm{TM}}$ ) using a CFX96 Real-Time PCR Detection System (Bio-Rad ${ }^{\mathrm{TM}}$ ). The primer sequences are reported in the supplementary material (suppl. Fig S2). The cycle threshold values were determined using the Bio-Rad CFX Manager Software v2.0 (Bio-Rad ${ }^{\mathrm{TM}}$ ). Results were analyzed using the $\Delta \mathrm{Ct}$ method (Livak and Schmittgen 2001) and normalization for housekeeping genes exactly as described earlier (Zimmer et al. 2011a, b; Weng et al. 2012, 2014).

\section{Results}

\section{Specific effects of IFN $\beta$ on human neural crest cell (NCC) migration}

In a previous study (Zimmer et al. 2014), IFN $\beta$ was found as a positive hit in a screen of drugs for potential developmental toxicity in human NCC. To confirm the effects of the cytokine IFN $\beta$ on human NCC migration, a new automated and operator-independent test method (Nyffeler et al. 2016) was used. NCC, generated from pluripotent stem cells, were allowed to migrate in the presence or absence of IFN $\beta$ for 48 h (Fig. 1a). Picomolar concentrations of IFN $\beta$ induced a significant inhibition of migration (Fig. 1b, left graph), as indicated by the reduced number of cells found in the migration zone (Fig. 1c). The migration capacity was reduced to $75 \%$ at $20 \mathrm{pM}$ (Fig. 1b, left graph), but IFN $\beta$ also affected the cell viability endpoint at this concentration (reduction of the cell number by $\sim 16 \%, p$ value $<0.01$ ). As no dead or dying cells were observed at any time point, the apparent 'reduction of viability' was most likely due to the known cytostatic effect of the cytokine (Bekisz et al. 2010).

For interpretation of the data from the MINC assay used here, it is important background information that NCC still proliferate during the assay. Thus, it is possible that drugs that inhibit proliferation, but not migration, show a false positive effect in the assay. Indeed, clear cell cycle inhibitors, like the DNA synthesis inhibitor aphidicolin, have been found to reduce the number of cells found in the migration area at the end of the experiment (Nyffeler et al. 2016). To exclude any effect on proliferation, we used the mitosis inhibitor cytosine arabinoside (AraC, $10 \mu \mathrm{M}$ ) as cell medium additive. Under such test conditions, any proliferation was blocked (Fig. 1d), and the specific effect of cytostatic drugs on migration can be quantified without interference of cell cycle effects. When the assay was repeated in the presence of AraC, IFN $\beta$ did not affect the viability endpoint at all, but it still triggered a significant inhibition of migration at $25 \mathrm{pM}$, and the threshold of $25 \%$ reduction (Zimmer et al. 2012, 2014; Nyffeler et al. 2016) was reached at $50 \mathrm{pM}$ (Fig. 1b, right graph). Thus, data from different test formats corroborated the earlier finding that $\mathrm{pM}$ concentrations of IFN $\beta$ reduced the migration of NCC, independent of any potential effects of the drug on NCC proliferation.

To investigate whether the effects observed were specific for IFN $\beta$ within the interferon family, related cytokines were also tested: IFN $\alpha$ and IFN $\gamma$. IFN $\alpha$ binds to the same receptor as IFN $\beta$, but with lower affinity. Accordingly, it affected migration only at much higher (two orders of magnitude) concentrations (Fig. 2a). In contrast to this, the type II interferon IFN $\gamma$ affected viability and the migration endpoint at low pM concentrations, similar to IFN $\beta$ (Fig. 2b). To unambiguously separate the effects on proliferation from those on migration, the interferons were tested under non-proliferating assay conditions (Fig. 2a, b), and both the $75 \%$ effective concentration (EC75) as well as the lowest effective concentration (LOAEL) were determined for the migration endpoint and compared to IFN $\beta$ (Fig. 3c). These experiments showed that IFN $\alpha$ inhibits migration of NCC, but that it was about two orders of magnitude less potent. The data also showed that IFN $\gamma$ mainly affected the NCC proliferation at low $\mathrm{pM}$ concentration, while specific effects of migration were only observed in the $\mathrm{nM}$ range. Thus, IFN $\beta$ is the only tested interferon that affected the migration of NCC at clinically relevant low pM concentrations.

As migration is a fundamental cell biological process, it may be assumed that the capacity of IFN $\beta$ to disturb cell movement may apply to many other cell types. However, it was shown earlier that many toxicants affect NCC migration without affecting, for example, tumor cells or other neural precursors (Zimmer et al. 2012). To study such specificity for IFN $\beta$, we used the human breast cancer cell line MDA-MD-231, which is highly metastatic, displays a mesenchymal/fibroblastoid phenotype (Prat et al. 2010), and thus migrates in a somewhat similar way as NCC. Under proliferating conditions, IFN $\beta$ showed potent effects (low pM range) on both the migration and the viability endpoints 

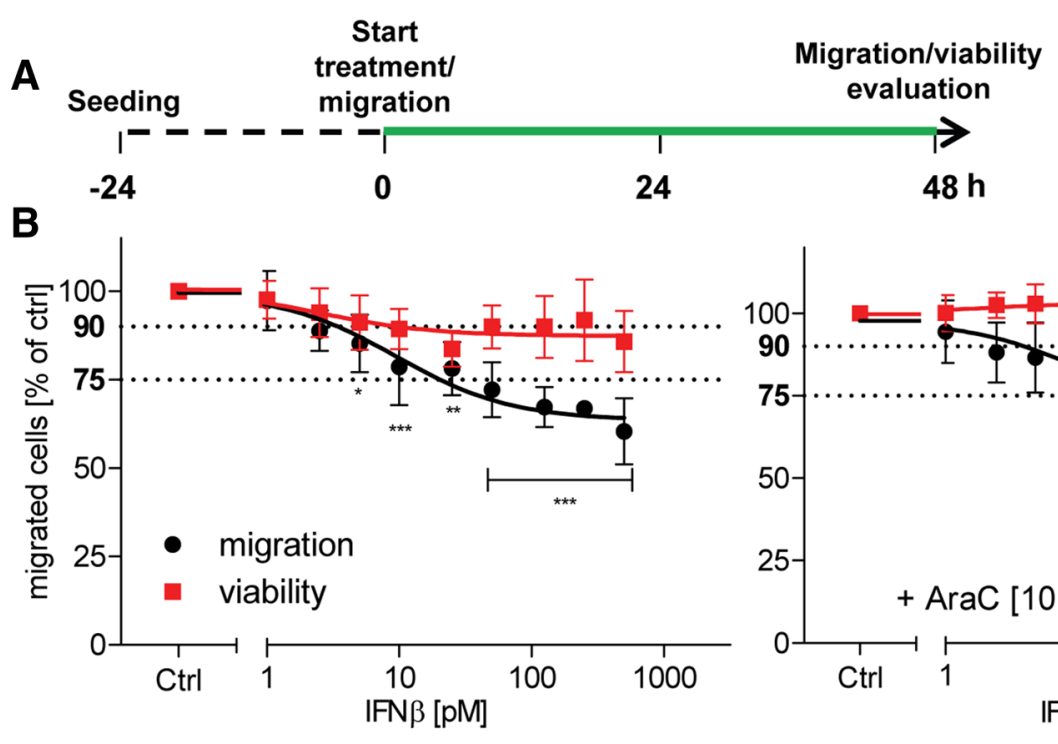

C
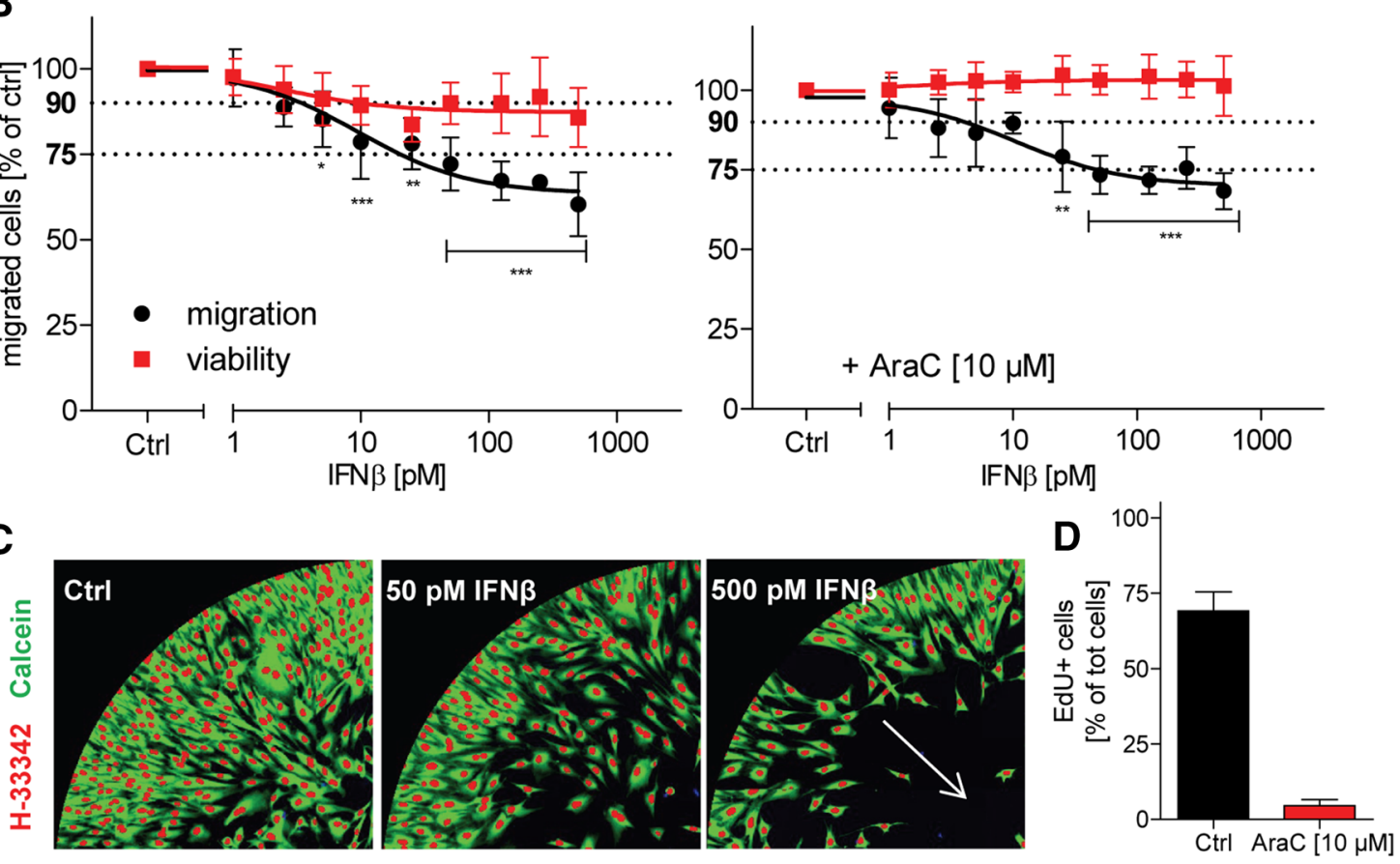

Fig. 1 Impaired migration of NCC in the presence of IFN $\beta$. a NCC were allowed to attach and recover for $24 \mathrm{~h}$. Then, migration was started and, $48 \mathrm{~h}$ later, the number of migrated cells and the viability of the cell population were quantified. In standard experiments, NCC were exposed to IFN $\beta$ (marked in green) for the entire migration period. b NCC were exposed to IFN $\beta$ at the indicated concentrations. Cell viability and the number of migrated cells are expressed relative to control cells (Ctrl, $0.1 \%$ BSA in PBS). In one series of experiments (right graph), the cell culture medium used for all conditions was supplemented with the mitosis inhibitor cytosine arabinoside $(\mathrm{AraC}, 10 \mu \mathrm{M})$. Data are from three independent experiments. Error bars indicate standard deviations (SD). Statistics was performed for each endpoint by ANOVA, followed by Dunnet's post-hoc

(Fig. 2d, left graph). Under test conditions that avoided any drug effects on proliferation, no inhibition of migration by IFN $\beta$ was detected (Fig. 2 d, right graph). Thus, the effect of IFN $\beta$ on the migration of cells did not apply to any cell type, but may be rather specific for NCC.

\section{Maintenance of basic functions and cell morphology after exposure to IFN $\beta$}

One straightforward explanation for the relatively specific effects of IFN $\beta$ on NCC migration may be a change of the cell differentiation state by the cytokine. For instance, a mesenchymal-to-epithelial (MTE) transition or a differentiation to a neural or other final cell type may reduce test $(* p \leq 0.05, * * p \leq 0.01, * * * p \leq 0.001)$. Viability was considered to be impaired when it dropped below $90 \%$; migration was considered to be impaired below 75\%, compared to control (dotted lines at 75 and $90 \%$ are indicated for visual support). c Representative pictures of different migration assay exposure scenarios, taken at time $48 \mathrm{~h}$. Nuclei are depicted in red (H-33342), while viable cells are shown in green (calcein). d NCC were exposed to culture medium supplemented with 5-ethynyl-2'-deoxyuridine (EdU, $10 \mu \mathrm{M})$ and they were treated with $\operatorname{AraC}(10 \mu \mathrm{M})$ or the respective control (Ctrl) for $48 \mathrm{~h}$. Then, cells were stained with H-33342 (nuclei), and EdU-positive cells (EdU+) were quantified. Cell proliferation was expressed as percentage of EdU + cells out of the total number of cell nuclei. (Color figure online)

spontaneous migration of the cells. Therefore, various cell features were studied. We examined several typical cell type-specific mRNA markers (e.g., MSX1, SOX9, SNAIL2, NRP1, and PAX3), and none of them changed their expression level upon exposure to IFN $\beta$ (suppl. Fig. S4). Moreover, the characteristic cell shape was maintained. To assess the latter finding in more detail, some molecular markers of cell structure were studied. NCC were treated with a maximal concentration of IFN $\beta$ (500 pM) for $48 \mathrm{~h}$. Then, the F-actin microfilaments were visualized with phalloidin. Mitochondrial structures were stained with an antibody to TOM20, and the Golgi apparatus was stained for the GM130 protein. Multiple images ( $>15)$ were recorded for each conditions, and two observes blinded to 


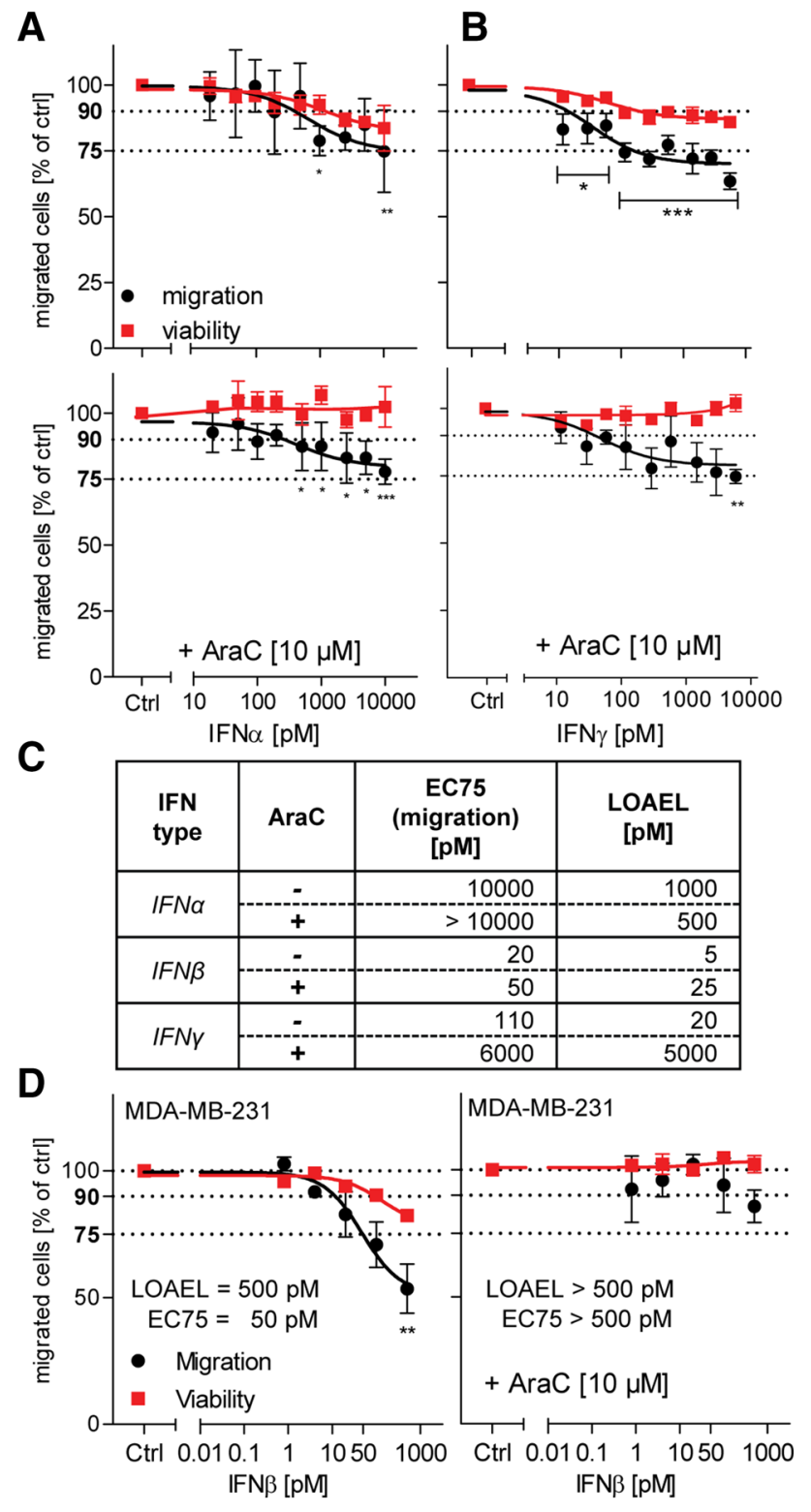

Fig. 2 Specificity of IFN $\beta$ effects on NCC. NCC were treated for $48 \mathrm{~h}$ with interferons, while they were allowed to migrate. Then, the viability and the inhibition of cell migration were measured. All assays were performed either with or without cytosine arabinoside (AraC, $10 \mu \mathrm{M})$ as culture medium supplement. a, b Testing of interferon- $\alpha$ (IFN $\alpha)$ and interferon- $\gamma$ (IFN $\gamma)$. Data are from three independent experiments. Error bars indicate standard deviations (SD). Statistics was performed for each endpoint by ANOVA, followed by Dunnet's post-hoc test $(* p \leq 0.05, * * p \leq 0.01, * * * p \leq 0.001)$. c $\mathrm{EC}_{75}$ and the lowest observed adverse effect level (LOAEL) were compiled for each scenario. The LOAEL was defined as the lowest concentration triggering a significant reduction of cell migration $(p \leq 0.05)$. d Human breast cancer cells MDA-MD-231 were allowed to migrate for $48 \mathrm{~h}$, before viability and the number of migrated cells were quantified. Cells were treated with the indicated concentrations of IFN $\beta$ for the total migration period, either with or without cytosine arabinoside (AraC, $10 \mu \mathrm{M}$ ) as culture medium supplement the treatment condition examined the cell features. No differences were observed that could be related to the treatment with IFN $\beta$ (Fig. 3a).

In a next step, various functions associated with cell adhesion were studied. The expression of 20 integrins and cadherins was studied, and none of them changed $>30 \%$ in the presence of IFN $\beta$ (suppl. Fig. S5). In a more functional approach, we assessed the phosphorylation (and activation) level of the focal adhesion kinase (FAK). Protein samples were prepared from NCC after 0,6 , or $24 \mathrm{~h}$ of adhesion, either with or without IFN $\beta(500 \mathrm{pM})$. Adhesion of the cells led to the activation of FAK, as expected. This process was not significantly affected by exposure to IFN $\beta$ (Fig. 3b).

In a third approach, we examined whether IFN $\beta$ may affect the response of cells to external stimuli, such as mitogenic or inflammatory cytokines. NCC were incubated without the growth factors EGF/FGF overnight, and then exposed to these cytokines in the presence of absence of IFN $\beta$. IFN $\beta$ alone neither triggered the MAP kinase pathways (as measured by phosphorylation of Erk) nor the Akt pathway (as measured by phosporylation of Akt). EGF/FGF clearly triggered these pathways and this effect was not affected by IFN $\beta$ (suppl. Fig. S6). Alternatively, NCC were exposed to inflammatory cytokines (CM: TNF $\alpha$ and IL1 $\beta$ ) to probe the response of the NFkB pathway. The CM triggered translocation of the transcription factor NFkB from the cytosol to the nuclei (Fig. 3c, upper panels) in $91 \pm 7 \%$ of all cells. IFN $\beta$ itself did not trigger NFkB translocation. Neither did it affect the signaling of the CM. (Fig. 3c, lower right panel). Thus, no obvious structural features and none of the tested signaling functions were impaired by exposure to IFN $\beta$.

\section{Attenuation of NCC migration speed and chemotactic behaviour by IFN $\beta$}

To confirm the impairment of NCC migration by IFN $\beta$, and to further exclude any artefacts due to drug effects on cell proliferation or differentiation, two other functional assays were used. The first approach made use of time lapse imaging and cell tracking to study effects on cell speed. Migrating cells were incubated with IFN $\beta$ on a microscope stage in a temperature-controlled incubation system (Fig. 4a). This setup allowed a continuous recording of phase contrast images for $30 \mathrm{~h}$. The image stacks were then used to track the migrating cells ( $\geq 10$ cells per well) (Fig. 4b). Analysis of the tracks revealed a concentration-dependent reduction of the accumulated distance travelled by IFN $\beta$ treated NCC, compared to control cells (Fig. 4c). Thus, this method confirmed on the single cell level that IFN $\beta$ reduced the migration speed. 
Fig. 3 Maintenance of basic NCC functions and morphology in the presence of IFN $\beta$. a NCC were treated with IFN $\beta(500 \mathrm{pM})$ or solvent $(\mathrm{Ctrl})$ for $48 \mathrm{~h}$, allowed to migrate in the last $6 \mathrm{~h}$ of the treatment period, and finally fixed for immunofluorescence staining. The microfilament cytoskeleton was visualized by phalloidin; antibodies to TOM20 were used to visualize mitochondria and anti-GM130 for the Golgi apparatus. b NCC were seeded for 0, 6, and $24 \mathrm{~h}$ (adhesion time) in culture medium supplemented with IFN $\beta(500 \mathrm{pM})$ or solvent. Then, cells were lysed and the amount of phosphorylated FAK was measured by Western blot analysis. The mean intensity of each band normalized to the respective loading control (GAPDH) \pm SD is reported below each condition $(n=3)$. In the control $(0 \mathrm{~h}=$ non-adherent cells), no band was detected. No significant change was observed between control and treatments at 6 and $24 \mathrm{~h}$. c NCC were exposed to a cytokine mix (CM, $10 \mathrm{ng} / \mathrm{ml} \mathrm{TNF} \alpha$, and $10 \mathrm{ng} / \mathrm{ml}$ IL1 $\beta)$, IFN $\beta$ $(500 \mathrm{pM})$ or a combination of both for $1 \mathrm{~h}$. Cells were then fixed and stained for nuclear factor $\mathrm{kB}$ (NFkB, green). Representative pictures for each condition are shown, with nuclei counterstained with H-33342 (red). Nuclei with translocated NFkB appear yellow, instead of red (non-translocated NFkB). (Color figure online)

The second approach made use of a transwell set-up. In this system, cells can be seeded onto a porous membrane in the upper compartment. When a chemoattractant (here FBS was used) is added to the bottom part, cells are triggered to migrate through the membrane. NCC were seeded on the transwell membrane directly or after a 42 -h pretreatment with IFN $\beta$. At the end of a 6-h migration period, cells that had translocated through the membrane were counted (Fig. 4d). NCC treated with IFN $\beta$ for the period from 0 to $48 \mathrm{~h}$ showed a significant reduction of their capacity to migrate through the membrane. NCC treated only during the last $6 \mathrm{~h}$ of the migration period (42-48 h) were not impaired (Fig. 4e). This set of data suggests that (1) the migration inhibition by IFN $\beta$ can also be measured in a different (here 3-dimensional) test setup; and (2) that cells must be exposed for $>6 \mathrm{~h}$ to IFN $\beta$ for the inhibition of migration to become apparent.

\section{Transcriptome changes and alterations of superordinate biological processes induced by IFN $\beta$ in NCC}

To obtain more data on the type of effects IFN $\beta$ has on NCC, cells were exposed for $48 \mathrm{~h}$ to the cytokine (500 $\mathrm{pM})$. Then, mRNA was prepared from five different cell lots and used for gene expression analysis by Affymetrix microarray technology. The data were compared to those obtained for seven toxicants and pharmaceuticals (arsenic trioxide, cyproconazole, PBDE-99, triadimefon, TSA, VPA, and geldanamycin) known to inhibit the migration of NCC (Zimmer et al. 2014; Pallocca et al. 2016). Each of the compounds was used at its respective highest non-cytotoxic concentration, and the data structure was visualized by a principal component analysis (Fig. 5a). Plotting of the first two principal components showed a strong separation

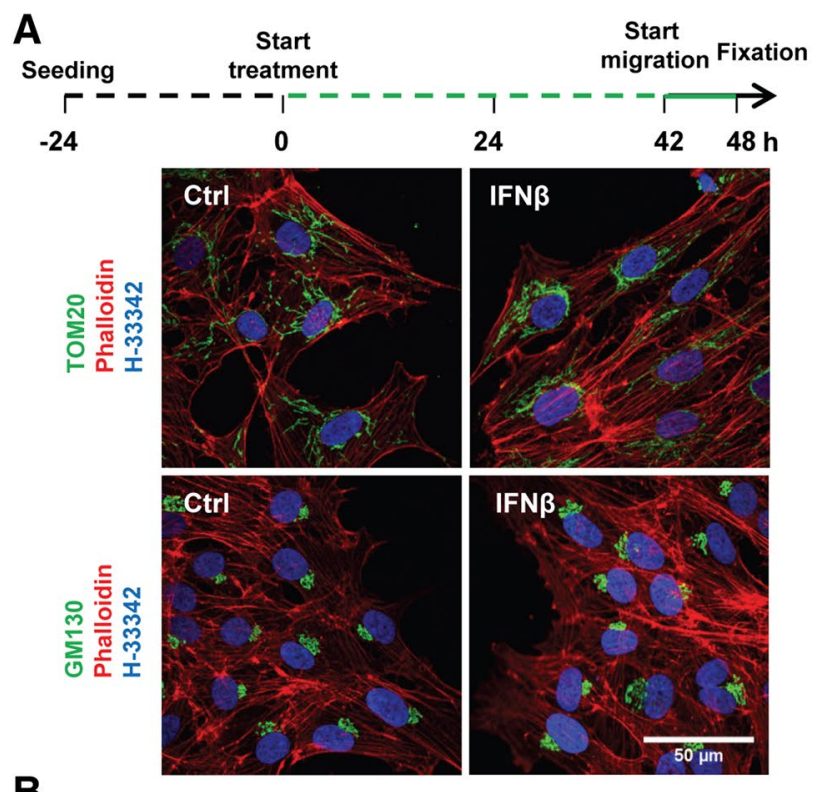

B

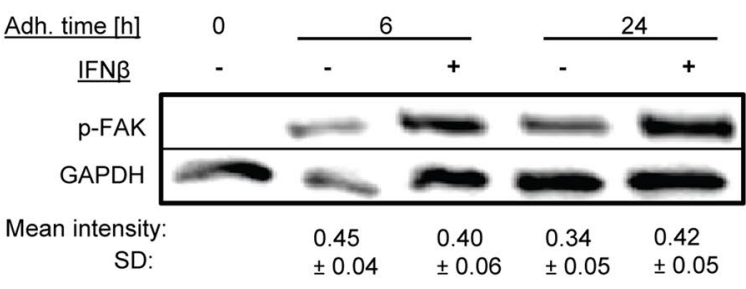

C
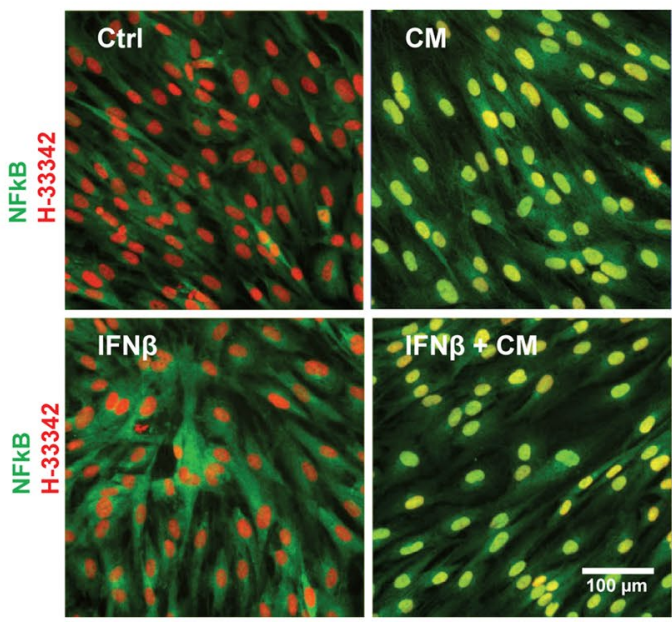

between IFN $\beta$-treated samples and all other samples along the first principal component axis. This was due to the much stronger gene regulation response triggered by IFN $\beta$, compared to small molecular weight toxicants.

The gene expression data were then used to determine the differentially expressed genes (DEG). The DEG for each toxicant were defined here as the group of microarray probe sets (PS), which differed significantly from negative controls (FDR adjusted $p$ value $\leq 0.05$ ), and showed expression level changes (fold change $(\mathrm{FC})$ ) of $\geq 1.8$ or 


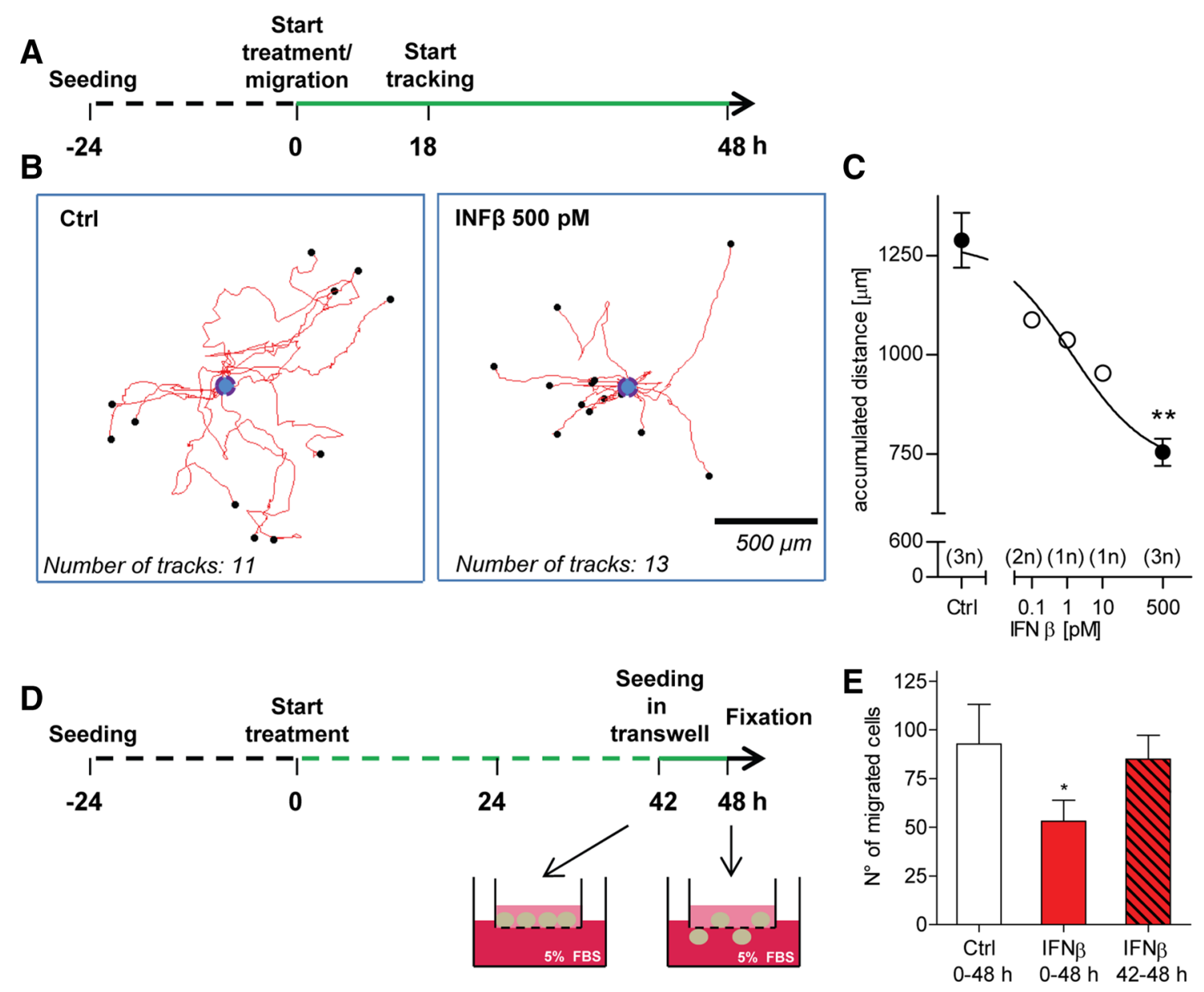

Fig. 4 Confirmation of impaired NCC migration in the presence of IFN $\beta$ in secondary functional assays. a NCC were allowed to migrate for $48 \mathrm{~h}$, and they were exposed to IFN $\beta$ at the indicated concentrations for the entire migration period. Phase contrast images were taken every 15 min during the last $30 \mathrm{~h}$ of migration for cell tracking. b Representative migration tracks for the control and $500 \mathrm{pM}$ IFN $\beta$ treated cells are shown. Tracks are normalized to the same starting point (blue circle); $x$ and $y$ dimensions are scaled similarly (see scale bar). c Averaged accumulated distance covered by the cells was then calculated for each test concentration. At least 10 cells were followed for each condition ( $=1$ technical replicate). The number of independent replicates for each condition is reported in the graph. Error bars indicate standard deviations (SD). Statistics is based on $t$ test

$\leq 0.55$ (Falsig et al. 2004; Pallocca et al. 2016). IFN $\beta$ triggered a much stronger up-regulation than down-regulation response, altering altogether 565 PS (Fig. 5b). To get more insight into the deregulated genes, the DEG were sorted according to their $p$ values and the top 20 up- and downregulated genes were displayed. Among the most strongly up-regulated genes, there were many IFN-induced proteins (IFI), which have mostly roles in the inhibition of viral replication. Other genes were the $2^{\prime}-5$ ' oligoadenylate synthetase family (OAS1/2), which activates the latent RNase $\mathrm{L}$, and induces viral RNA degradation; another typical analysis between control and maximal IFN $\beta$ concentration samples $\left(*^{*} p \leq 0.01\right)$; an ANOVA across all data, followed by Dunnet's posthoc test yielded the same significance level for $500 \mathrm{pM}$ IFN $\beta$. d NCC pre-treated for $42 \mathrm{~h}$ with IFN $\beta$ or solvent were seeded into transwells. Then, the cells were induced to migrate through the transwell porous membrane by addition of 5\% FBS into the lower chamber of the transwell, in the presence of IFN $\beta(500 \mathrm{pM})$ or respective control. After additional $6 \mathrm{~h}$ in the presence or absence of IFN $\beta$, migrated cells were stained with crystal violet. Four fields per replicate were imaged, and the cells were counted. e Quantification of the number of migrated cells for the different conditions: the total IFN $\beta$ exposure period is indicated; data are from four independent experiments. Error bars indicate standard deviations (SD). $* p \leq 0.05$. (Color figure online)

biomarker of IFN anti-viral responses was the MX dynamin like GTPase (MX1). In addition, we found a strong upregulation of the chemokine response (CXCL10 and 11). The group of strongly down-regulated genes was more heterogeneous. It comprised, for instance, the TNF receptor superfamily member TNFRSD10D, argonaute 1 (AGO1, the catalytic component of the RISC complex involved in the RNA interference process), and the zinc-dependent metalloprotease tolloid-like (TLL2) (Fig. 5c).

As the analysis of individual genes did not directly indicate which migration-related pathways may be impaired, 


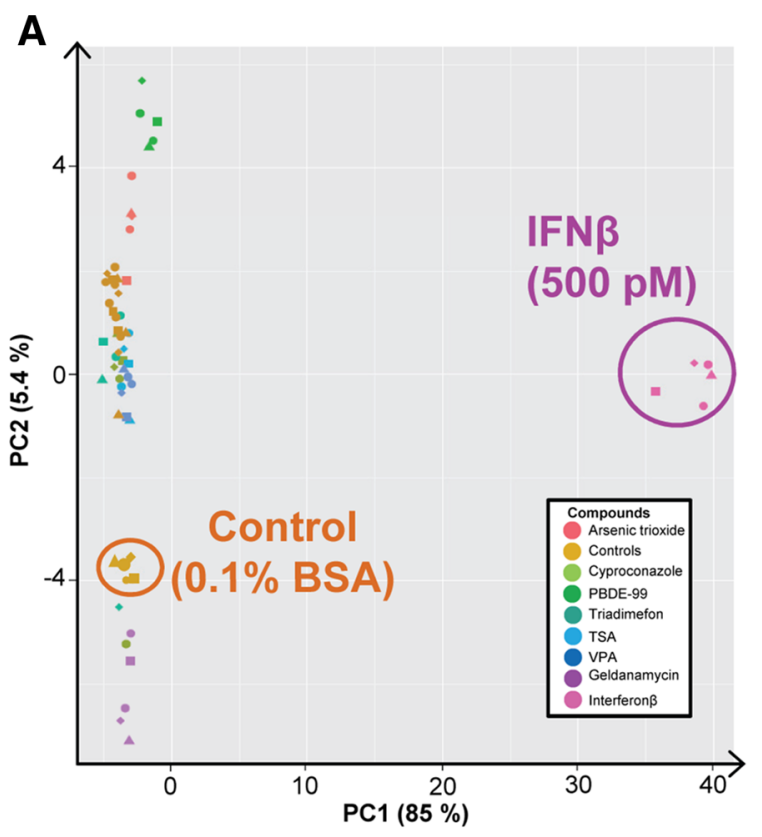

B

C

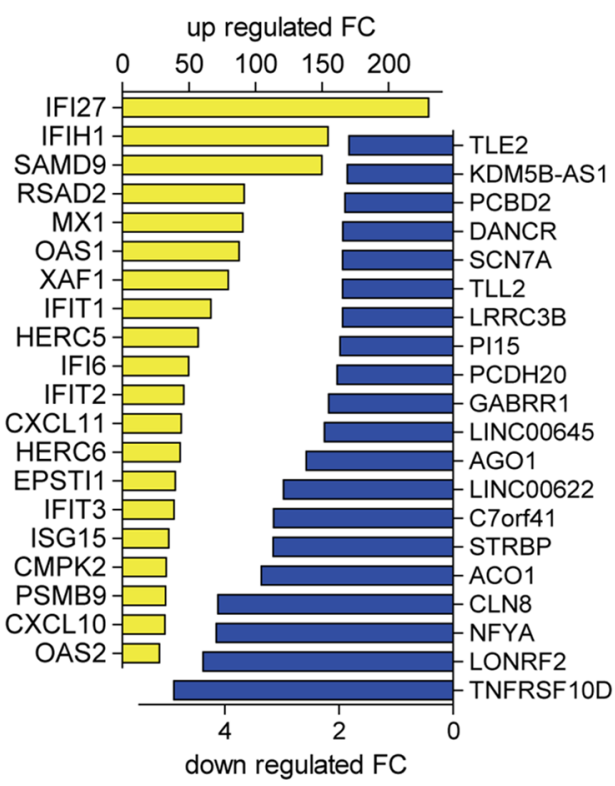

\begin{tabular}{|c|c|c|}
\hline $\begin{array}{c}|F C| \geq 1.8 \\
\text { Adj } p \text { value } \\
\leq 0.05\end{array}$ & $\underline{\mathrm{UP}}$ & DOWN \\
\hline$D E G$ & 469 & 96 \\
\hline GO & 567 & 24 \\
\hline KEGG & \multicolumn{2}{|c|}{$(2)$} \\
\hline \multicolumn{3}{|c|}{$\begin{array}{l}\text { - ANTIGEN PROCESSING AND } \\
\text { PRESENTATION }(n=15) \text {; } \\
\text { - CYTOKINE-CYTOKINE RECEPTOR } \\
\text { INTERACTION }(n=17)\end{array}$} \\
\hline
\end{tabular}
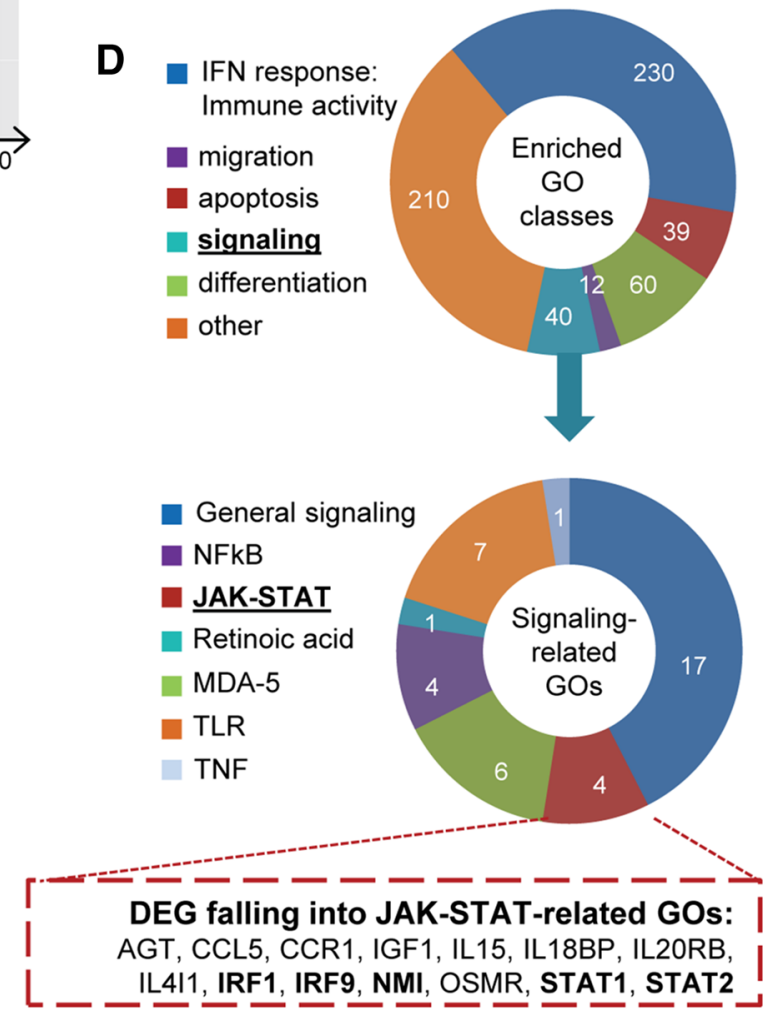

Fig. 5 Transcriptome changes triggered by IFN $\beta$ in NCC. Sampling for microarray analysis was performed in NCC after 48-h exposure to non-cytotoxic, but migration-inhibiting, concentrations of eight test battery hits, as identified in Zimmer et al. (2014). Data are from five independent experiments (= data points of one colour, but different shapes). a Principal component analysis (PCA) was performed, and a $2 \mathrm{D}$ plot was generated to display the transcriptome data structure across compounds and experimental replicates. The positions of IFN $\beta$-exposed samples, and the respective control, are circled. On the axes, the first two principal components are plotted, and the percentage of covered variances is reported. b Number of differentially up-regulated $(U P)$ or down-regulated $(D O W N)$ genes (DEG, IFN $\beta$ vs control) and the corresponding biological processes (over-represented GO classes) was identified. Over-represented KEGG pathways were searched amongst all DEG (UP and $D O W N)$, and the only

two significant pathways are indicated. c Identified DEG were sorted according to their $p$ value. The top 20 up- (yellow) and down- (blue) regulated genes are shown as bar graphs indicating the fold change (FC). Large regulation factors were observed especially for genes that showed very low expression in untreated cells (as is common for transcriptome analysis of inflammatory situations). The effect is unlikely to be due to baseline variations, as the sorting was done according to the $p$ value for the regulation. $\mathbf{d}$ Ring diagrams show the relative distribution of 6 superordinate biological processes (IFN response, migration/chemotaxis, apoptosis, signaling, differentiation, and other) amongst the over-represented GO classes (upper ring) and the number of the different signaling-related over-represented GO classes (lower ring). Genes with a central role in the JAK-STAT pathway are depicted in bold. (Color figure online) 
we investigated whether biologically linked groups of genes were co-ordinately regulated. More than 500 gene ontology (GO) terms were enriched (adjusted $p$ value $\leq 0.05$ ) amongst the up-regulated genes, while only 24 terms were over-represented amongst the down-regulated genes. To get a better idea on co-ordinately affected pathways, we also identified over-represented KEGG pathways amongst the sum of DEG. The two pathways found by this approach were "antigen processing and presentation" (15 genes represented) and the "cytokine-cytokine receptor interaction" pathway (17 genes represented). This was not surprising, given a main role of interferons in these processes (Fig. 5b), but it did not offer an evident explanation, why migration was impaired.

To get an overview of the over-represented GO groups, we assigned them to six superordinate cell biological processes (Waldmann et al. 2014): IFN responses, migration, apoptosis, signaling, differentiation, and others. As expected, most of the enriched GO classes belonged to the "IFN response group" (230 GO term groups). We focused on the signaling-related over-represented GO terms (40 groups) to get some hints regarding the mode of action of IFN $\beta$ on the migration capacity of NCC. Several GO in this group related to innate immunity and inflammatory signaling. Amongst the more general signal transduction pathways, only the JAK-STAT pathway was clearly overrepresented (4 GO groups) with several key players of this pathway being up-regulated (Fig. 5d). For this reason, we decided to examine the role of JAK-STAT signaling on NCC migration more directly.

\section{Correlation of IFN $\beta$-induced inhibition of NCC migration and JAK-STAT pathway activation}

As readout for JAK-STAT activation, we chose to analyze the phosphorylation level of one of the members of the STAT family, STAT1. This step is necessary for the heterodimerization of STAT proteins, which together with IRF9 form, and then the transcription factor IFN-stimulated gene factor 3 (ISGF3), and promotes IFN-induced genes transcription. Western blot analysis showed an increase of p-STAT1 in NCC after stimulation with both IFN class I interferons, with IFN $\alpha$ being about 100 -fold less potent than IFN $\beta$ (Fig. 6a, b). The extent of STAT1 phosphorylation was quantified, and it correlated with the extent to which migration was inhibited. This data set showed clearly that p-STAT1 levels correlated with the inhibition of migration in the case of IFN $\beta$ treatment (Fig. 6c). To reach 50\% of STAT1 phosphorylation, NCC needed to be exposed to $2 \mathrm{nM}$ of IFN $\alpha$ (vs $5 \mathrm{pM}$ IFN $\beta$ ), but also for IFN $\alpha$, the increase of pSTAT1 correlated with inhibition of migration (Fig. 6d). To evaluate a specific role of JAK-STAT signaling, we also examined phosphorylation of extracellular signal regulated kinases
A

IFN $\beta$
[pM]: 0

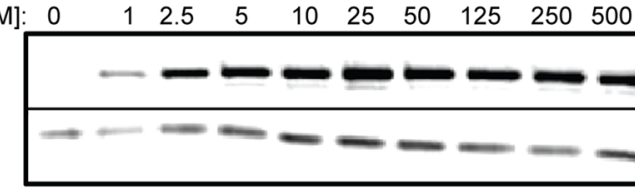

C

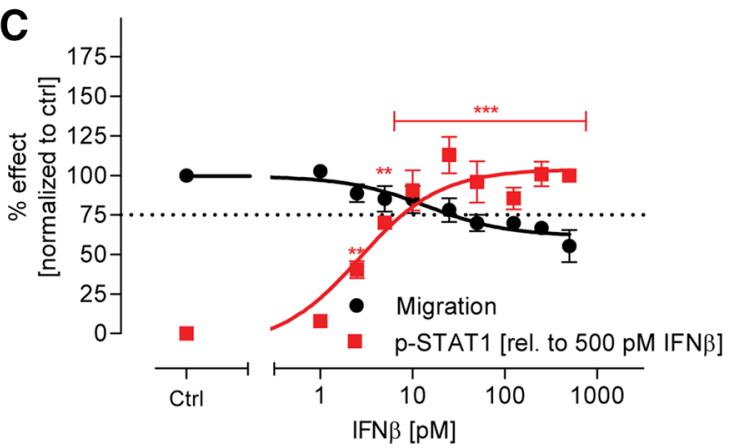

Fig. 6 Correlation between JAK-STAT pathway activation and inhibition of NCC migration upon treatment with class I IFN. a, b NCC were exposed to the indicated concentrations of IFN $\beta$ and IFN $\alpha$ for $1 \mathrm{~h}$. Then, cells were harvested and protein samples were prepared. The amount of phosphorylated STAT1 (p-Tyr701) was measured by western blot analysis (representative blots are shown). c, d Band
B
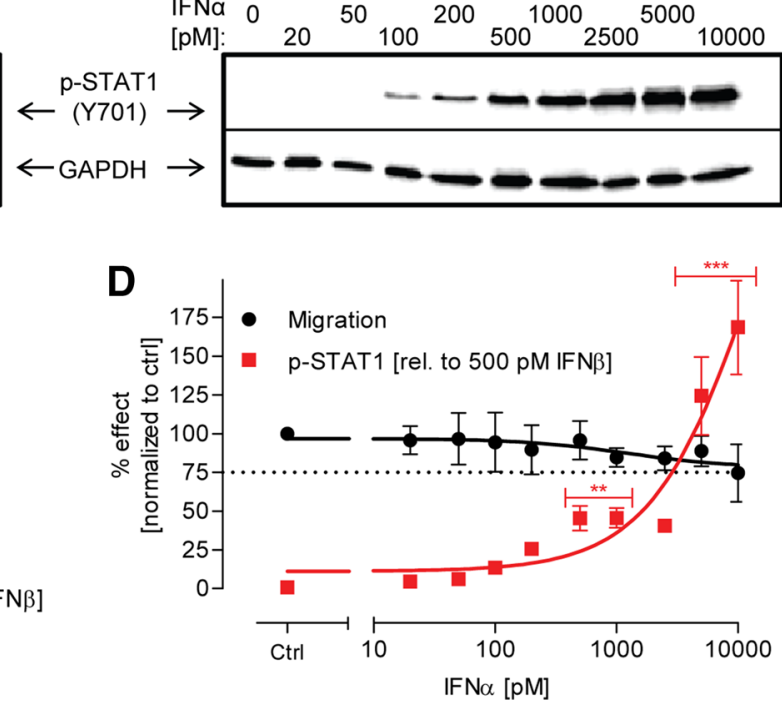

intensity was quantified and normalized to the respective GAPDH antibody band. For better comparison, the migration inhibition data from Fig. 1b are shown in black in the same graph. Data are means from three independent experiments. Error bars indicate standard deviations (SD). Statistical analysis was based on ANOVA, followed by Dunnet's post-hoc test $(* p \leq 0.05, * * p \leq 0.01, * * * p \leq 0.001$ ) 
(ERK1/2), of protein kinase B (AKT), and of glycogen synthase kinase-3 $\beta$ (GSK3 $\beta$ ), but none of them was changed by exposure to IFN $\beta$ (suppl. Fig. S6).

To obtain more causal evidence for the role of the JAKSTAT pathway in the inhibition of NCC inhibition, we used two different and specific JAK inhibitors (ruxolitinib and tofacitinib) to block the kinase signaling. Both inhibitors blocked STAT1 phosphorylation concentration-dependently (Fig. 7a, b). Moreover, exposure to ruxolitinib completely abolished the activation of eight different interferon target genes in cells exposed to IFN $\beta$ (Fig. 7c). A pharmacological block by any of the two inhibitors of the pathway resulted in the complete prevention of adverse effects of IFN $\beta$. Moreover, the extent of signaling pathway inhibition correlated significantly $(p<0.01)$ with the rate of reversal of the intereferon-beta effect (Fig. 7d, e).

\section{Requirement for continued JAK-STAT signaling for impairment of NCC migration}

Having established that the adverse effects of IFN $\beta$ on the migration of NCC are signaled via the JAK-STAT pathway, we were interested in the role of short vs continued exposure to interferons. To address this question, we exploited the rescuing effect of the JAK inihibitor ruxolitinib to terminate the IFN $\beta$ signaling at defined time points.

The standard migration assay, as described in 3.1, was performed in the presence of IFN $\beta$ (or respective
A Ruxolitinib (Rux)

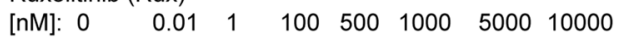

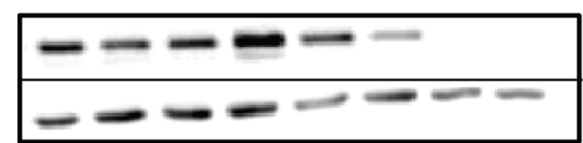

B

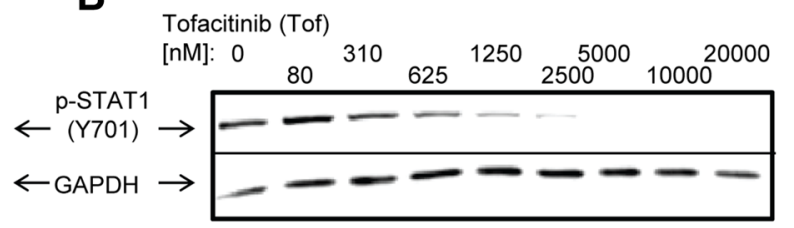

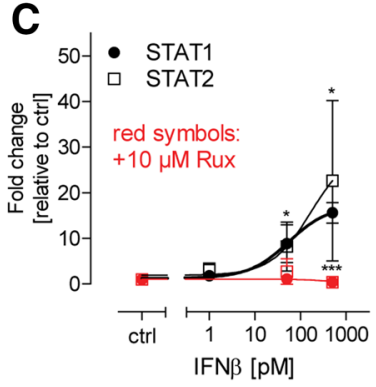

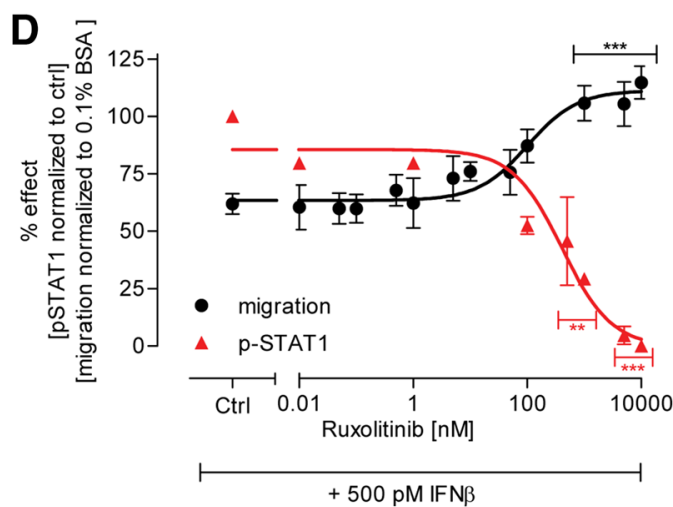

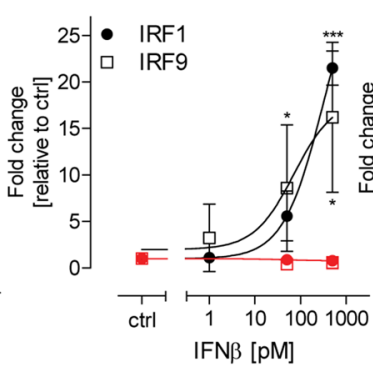
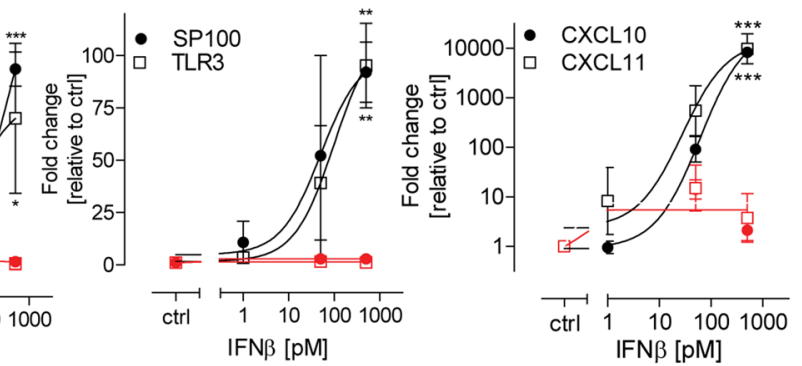

E

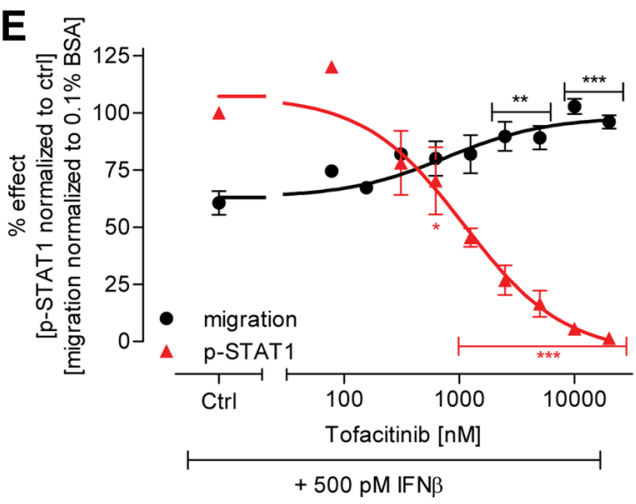

Fig. 7 Abolishment of the effect of IFN $\beta$ on NCC migration by inhibition of the JAK-STAT pathway. a, b NCC were pre-treated for $0.5 \mathrm{~h}$ with two different JAK inhibitors (ruxolitinib and tofacitinib) at the indicated concentrations. Then, the cells were further treated for $1 \mathrm{~h}$ with the inhibitors in cell culture medium supplemented with $500 \mathrm{pM}$ IFN $\beta$. Finally, cells were harvested and the amount of phosphorylated STAT1 (p-STAT1) was measured by western blot analysis (representative blots are shown). $\mathbf{c}$ NCC were exposed to IFN $\beta$ for $48 \mathrm{~h}$ at the indicated concentrations, either with or without ruxolitinib (Rux, $10 \mu \mathrm{M})$. Then, cells were harvested, and total RNA was extracted and retro-transcribed. Effects on selected mRNAs were evaluated by qPCR. Expression levels were normalized against the housekeeping gene, GAPDH and are expressed relative to control levels (untreated cells). The mRNA expression in the presence of Rux is shown in red. Note that the red symbols are often overlapping, due to complete inhibition down to control levels. d, e Band intensities were quantified for p-STAT1 (normalized to GAPDH). In a parallel set of experiments, migration (after $48 \mathrm{~h}$ ) was evaluated in the presence of IFN $\beta$ $(500 \mathrm{pM})$ plus ruxolitinib (left) or tofacitinib (right). Data are from three independent experiments. Error bars indicate standard deviations (SD). Statistics was performed by ANOVA, followed by Dunnet's post-hoc test $\left(* p \leq 0.05,{ }^{* *} p \leq 0.01, * * * p \leq 0.001\right)$. (Color figure online) 
control). Ruxolitinib was added to the cells immediately or at various time points after exposure to interferon. The inhibition of migration was then evaluated at $48 \mathrm{~h}$ for various experimental conditions (Fig. 8a). The results from these experiments showed that the inhibition of migration (by IFN $\beta$ ) was rescued when the inhibitor ruxolitinib was added not later than $6 \mathrm{~h}$ after the beginning of IFN $\beta$ treatment. When ruxolitinib was added after $10 \mathrm{~h}$ (or later), inhibition of migration (by at least 25\%) occurred (Fig. 8b). Thus, inhibition of migration by IFN $\beta$ required receptor signaling for at least $6-10 \mathrm{~h}$, while activation of the JAK-STAT pathway for up to $6 \mathrm{~h}$ hardly affected the migration capacity of NCC (Fig. 8b).

This finding was corroborated when standard migration assays were performed and IFN $\beta$ was washed out after $3 \mathrm{~h}$. Under these conditions, no inhibition of cell migration was observed (data not shown).

\section{Discussion}

In the present study, a potential developmental toxicity hazard of IFN $\beta$ with regard to NCC disturbance was confirmed. Migration of NCC was affected at low pM concentrations by IFN $\beta$, while IFN $\alpha$ was substantially (two orders of magnitude) less potent, and IFN $\gamma$ did not affect migration in the $\mathrm{pM}$ range. The effect on migration clearly differed from the cytostatic activity of the cytokines, as (1) IFN $\beta$ and IFN $\alpha$ had similar cytostatic potency on the test system, and (2) as cytostatic and migration-inhibiting properties could be experimentally separated. Moreover, the specific effect of IFN $\beta$ on migration was confirmed in assays with different protocols and endpoints. A closer cell biological characterization showed that the inhibition of migration correlated well with a prolonged activation of the JAK-STAT signaling pathway in various sets of experiments. Thus, prolonged activation of STAT1 by IFN $\beta$ in
Fig. 8 Requirement for continued JAK-STAT signaling to NCC migration impairment. a NCC were allowed to migrate for $48 \mathrm{~h}$. During this time, they were exposed to IFN $\beta$ while ruxolitinib $(10 \mu \mathrm{M})$ was added to the culture medium at different time points after the start of the migration. The percentage of migrated cells was quantified for all conditions after $48 \mathrm{~h}$. Migration was inhibited $\geq 25 \%$ in all conditions denoted in blue. Ruxolitinib without IFN $\beta$ had no effect on migration. $\mathbf{b}$ Graphical representation of the effects of IFN $\beta$ and JAK-STAT pathway-inhibitors on the transcription of target genes and on the functionality of NCC.

NCC migration was unimpaired in the absence of IFN $\beta$ or when IFN $\beta$ was present together with ruxolitinib. NCC migration was impaired when IFN $\beta$ was present alone, or when ruxolitinib was added $\geq 10 \mathrm{~h}$ after IFN $\beta$. (Color figure online)
A
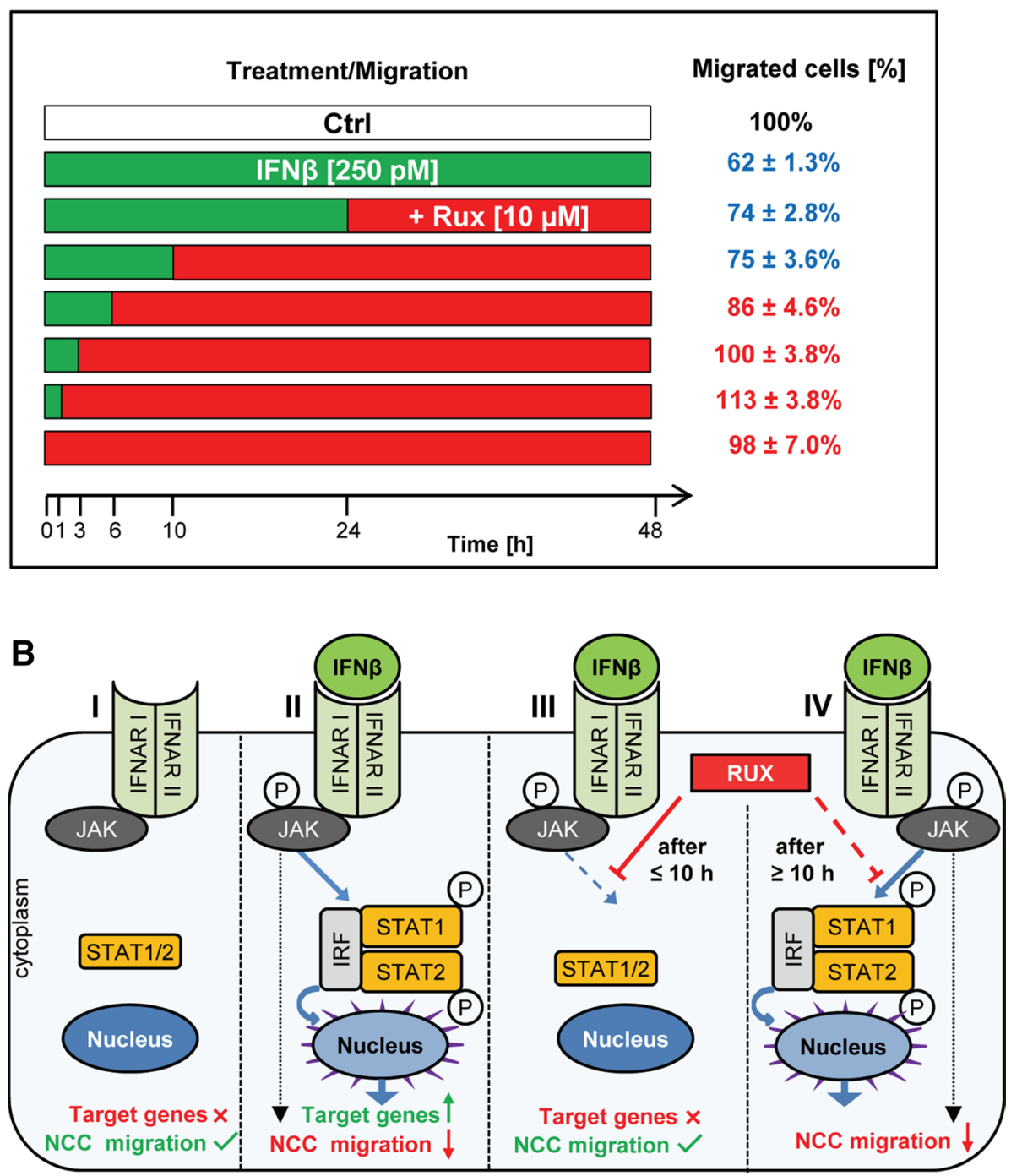
NCC provides a biochemical marker of potentially adverse effects of IFN $\beta$ on fetal development during pharmacological use.

As IFN $\alpha$ and IFN $\beta$ signal through the same receptor complex, the largely different potencies observed here may appear surprising. However, such observations are explained by the higher affinity of IFN $\beta$ (compared to IFN $\alpha$ ) for the shared receptor subunits. A more pronounced effect of IFN $\beta$ has also been observed in other test systems. For instance, only IFN $\beta$ induced JAK1 activation in human myocardial fibroblasts, and this was associated with a 120fold higher potency to trigger an anti-viral response (vs IFN $\alpha$ ) (Heim et al. 1996; Grumbach et al. 1999); also in human vascular endothelial cells, a 2-3 log difference was observed for IFN $\beta$ vs IFN $\alpha$ in functional assays (da Silva et al. 2002), and IFN $\beta$ was 100 -fold more potent than IFN $\alpha$ with respect to the inhibition of differentiation of human monocytes into osteoclasts (Coelho et al. 2005). Notably, the difference in affinity is only relevant for the biological effect in cells that express low numbers of receptors; in cells with a high receptor reserve, functional effects are observed for both type I interferons within the same concentration range (van Boxel-Dezaire et al. 2006; Moraga et al. 2009; Schreiber and Piehler 2015). As high and low receptor numbers are not an absolute measure, but relate to the percentage of receptors required to trigger a full biological response in a given cell type, the potency difference of IFN $\alpha$ and IFN $\beta$ may differ for different responses within one given cell (Zula et al. 2011; Piehler et al. 2012). From these considerations, widely accepted in the interferon literature, we conclude that NCC express low numbers of the receptor subunits IFNAR1 and IFNAR2 on their surface. Moreover, we may conclude that a higher occupancy is required to affect migration than to trigger a cytostatic effect.

To our knowledge, effects of IFN $\beta$ on the migration of neural cells or their precursors have not been reported yet. However, the migration and invasion properties of glioma cells are affected by interferon-regulated genes (Yu et al. 2011; Tarassishin and Lee 2013) and neuronal survival seems to require a basic level of interferon signaling (Ejlerskov et al. 2015). Moreover, interference of $\operatorname{IFN} \beta$ with migration has been shown especially in the leukocyte lineage of cells (Lou et al. 1999; Staun-Ram and Miller 2011; Floris et al. 2002) and for various tumor cells (Booy et al. 2015; Rossi et al. 2015). Many of these studies suggest that cell migration may be affected by interferons through a reduced secretion of matrix metalloproteases (Stuve et al. 1997; Yen et al. 2010). This mechanism is unlikely to play a role in the experimental systems used in our study, as the penetration of extracellular matrix is not required for twodimensional NCC migration. As IFN $\beta$ is extremely pleiotropic in its activities, great care is required to distinguish effects that are correlated with reduced migration and effects that causally lead to reduced migration.

In the present study, we found that JAK-STAT signaling is a causal factor involved in reduced migration. In parallel, we invested major efforts to avoid erroneous conclusions, based on secondary effects triggered by IFN $\beta$. These experiments followed two main lines. First, we made sure that migration was specifically affected, and that test results were not an indirect consequence of the known cytostatic effects of interferons (Bekisz et al. 2010). These precautions are particularly important for slowly migrating cells (as NCC), while such controls are less common in the field of leukocyte migration. One taken approach was to run the assay under conditions that did not allow any proliferation (presence of a mitosis inhibitor). IFN $\beta$ showed its effect on migration also in this setup. The second approach was to use an assay with a faster readout (transwell assay), and then, going one step further, we followed individual cell migration directly by tracking. In addition, these experiments confirmed the inhibition of migration in a low $\mathrm{pM}$ range of IFN $\beta$.

Second, we provided evidence that IFN $\beta$ treatment did not obviously alter the cell differentiation state. In theory, extracellular signals may lead to the differentiation of NCC to neurons or other progeny that are less prone to migration. This is unlikely to happen in our test system, as several differentiation markers remained unchanged, as a characterization on the organellar level did not reveal differences after treatment with IFN $\beta$, and as key molecules relevant to adhesion and migration, like focal adhesion kinase or expressed integrins, remained unaffected. The stability of the overall NCC phenotype is remarkable, especially in the light of the transcriptome analysis, which showed that a typical (anti-viral and immunomodulatory) interferon response was triggered on the level of gene expression. Most conspicuous amongst these regulated transcripts were several chemokines and chemokine receptors (CCL5, CXCL10, CXCL11, and CCR1), but the changes were observed too late to be relevant for the effects on migration observed here. Moreover, the migration of NCC was not affected in our assay by chemokine receptor antagonists (not shown).

Several sets of data presented here suggest that the extent of activation of the JAK-STAT pathway correlates with inhibited migration by IFN $\beta$. Moreover, we also explored the temporal relationship of this pathway activation with NCC motility. It is known that cytokines, like interferons, may either trigger a hit-and-run signaling response (Brask et al. 2004), i.e., short formation of the receptor-ligand complex has long-acting or irreversible effects, or they may lead to an acute cellular change reversible after termination of cytokine-receptor interaction. In other cases of cytokine action, prolonged receptor signaling is required to 
trigger downstream cellular processes, and once triggered the cellular alterations may remain stable. Here, we found an example of the latter response pattern: activation of the JAK-STAT pathway for less than $6 \mathrm{~h}$ had no significant effect on cell migration; activation for more than $10 \mathrm{~h}$ was sufficient to trigger the full response, also when the kinase pathway was then blocked by specific inhibitors. This suggests that short peak levels of the cytokine would not affect NCC migration in a fetus, but if such levels are maintained in chronic infection, or after transfer of pharmacologically applied IFN $\beta$ across a compromised placental barrier, adverse developmental effects may follow.

In this context, it is important that interferons show a high degree of species-specificity. The evaluation of the effects of human IFN $\beta$ is, therefore, not possible in rodent or rabbit models, and only some monkeys (e.g., rhesus monkeys) show pharmacodynamic responses to the cytokine. Concerning the pharmacokinetic behaviour, the most relevant data come from clinical trials. IFN $\beta$ is normally given to MS patients intramuscularly at a dose of 6 million international unites (MIU) (Barbero et al. 2004). In controlled pharmacokinetic studies, 12 MIU IFN $\beta$ given intramuscularly to healthy patients led to a $\mathrm{C}_{\max }$ of $44 \mathrm{IU} /$ $\mathrm{ml}$, corresponding to $\sim 9 \mathrm{pM}$ (Alam et al. 1997). A rough linear approximation would suggest that the clinical dose used in MS would lead to peak plasma levels of 4-5 pM, i.e., roughly within the range of the concentrations found to affect NCC here. In a previous study (Zimmer et al. 2014), we calculated the dose to result in developmental toxicity to monkeys (FDA 1999) to correspond to plasma levels of $540 \mathrm{pM}$. This concentration is higher than the concentrations found here to affect human NCC, but the data basis is relatively limited and the concentration estimate requires several assumptions for the PBPK modelling (Zimmer et al. 2014). Unfortunately, retrospective clinical studies do not provide a clearer set of information. The safety of IFN $\beta$ in pregnancy has been observed on several occasions, but with contrasting results (Sandberg-Wollheim et al. 2005). To date, women with MS are advised to interrupt the exposure to the drug for precautionary reasons (Lu et al. 2012; Pozzilli and Pugliatti 2015), but information on no-effect levels or critical windows of susceptibility are not available.

In the absence of clear clinical data, and in the pertinent case of highly species-specific effects of the drug, our human cell-based testing approach allowed important insights into potential toxicological hazard, and into the concentration range at which this may be expected. In this context, it is important that the phenotypic adverse effect (inhibited migration) was consistent with a plausible biochemical mechanism of IFN $\beta$ signaling (JAK kinase activation), that exact information on the relevant concentration range was obtained, and that several tests and endpoints confirmed the type of potential hazard identified in initial studies. On the basis of this example study, we suggest that a combination of cellular tests based on relevant human cell types and engineered tissue structures (e.g., placental barrier) be used more frequently to obtain information on toxicological properties of human-specific drugs.

Acknowledgements We are grateful to Ms H. Leisner, D. Fischer, and M. Kapitza for invaluable experimental support. We are also indebted to many colleagues for valuable contributions and insightful discussions during the course of this work. We also thank the FACS and bioimaging (BIC) facility of the University of Konstanz. The help of Prof. W Parson, (Forensic Medicine, Innsbruck) for STR typing of cells is gratefully acknowledged. This work was supported by grants and support from the Doerenkamp-Zbinden foundation; the German research foundation (research training group 1331 and KoRS-CB), the land BW, the EC H2020 EU-ToxRisk project, and the University of Konstanz AFF.

\section{Compliance with ethical standards}

Conflict of interest The authors declare no conflict of interest.

Open Access This article is distributed under the terms of the Creative Commons Attribution 4.0 International License (http:// creativecommons.org/licenses/by/4.0/), which permits unrestricted use, distribution, and reproduction in any medium, provided you give appropriate credit to the original author(s) and the source, provide a link to the Creative Commons license, and indicate if changes were made.

\section{References}

Alam JMA, Scaramucci J, Jones W, Rogge M (1997) Pharmacokinetics and pharmacodynamics of interferon Beta-la (IFN $\beta-1 \mathrm{a})$ in healthy volunteers after intravenous, subcutaneous or intramuscular administration. Clin Drug Investig 14:35. doi:10.2165/00044011-199714010-00005

Alexa A, Rahnenfuhrer J, Lengauer T (2006) Improved scoring of functional groups from gene expression data by decorrelating GO graph structure. Bioinformatics 22(13):1600-1607. doi:10.1093/bioinformatics/btl140

Amato MP, Portaccio E, Ghezzi A, Hakiki B, Zipoli V, Martinelli V et al (2010) Pregnancy and fetal outcomes after interferon-beta exposure in multiple sclerosis. Neurology 75(20):1794-1802. doi:10.1212/WNL.0b013e3181fd62bb

Aschner M, Ceccatelli S, Daneshian M, Fritsche E, Hasiwa N, Hartung T, et al. (2017) Reference compounds for alternative test methods to indicate developmental neurotoxicity (DNT) potential of chemicals: example lists and criteria for their selection and use. Altex 34(1):49-74 doi:10.14573/altex.1604201

Balmer NV, Weng MK, Zimmer B, Ivanova VN, Chambers SM, Nikolaeva E et al (2012) Epigenetic changes and disturbed neural development in a human embryonic stem cell-based model relating to the fetal valproate syndrome. Hum Mol Genet 21(18):4104-4114. doi:10.1093/hmg/dds239

Barbero P, Verdun E, Bergui M, Pipieri A, Clerico M, Cucci A et al (2004) High-dose, frequently administered interferon beta therapy for relapsing-remitting multiple sclerosis must be maintained over the long term: the interferon beta dose-reduction study. $\mathbf{J}$ Neurol Sci 222(1-2):13-19. doi:10.1016/j.jns.2004.03.023 
Bekisz J, Baron S, Balinsky C, Morrow A, Zoon KC (2010) Antiproliferative properties of Type I and Type II interferon. Pharmaceuticals (Basel) 3(4):994-1015 doi:10.3390/ph3040994

Benjamini YHY (1995) Controlling the false discovery rate: a practical and powerful approach to multiple testing. J R Stat Soc Ser B Stat Methodol 57:289-300

Booy S, van Eijck CH, Janssen JA, Dogan F, van Koetsveld PM, Hofland LJ (2015) IFN-beta is a potent inhibitor of insulin and insulin like growth factor stimulated proliferation and migration in human pancreatic cancer cells. Am J Cancer Res 5(6):2035-2046

Brask J, Kristensson K, Hill RH (2004) Exposure to interferongamma during synaptogenesis increases inhibitory activity after a latent period in cultured rat hippocampal neurons. Eur J Neurosci 19(12):3193-3201. doi:10.1111/j.0953-816X.2004.03445.X

Carlson M (2015) hgu133plus2.db: Affymetrix Human Genome U133 Plus 2.0 Array annotation data (chip hgu133plus2). R package version 3.0.0. http://biocismacjp/packages/30/data/annotation/ manuals/hgu133plus2db/man/hgu133plus2dbpdf

Coelho LF, de Freitas Almeida GM, Mennechet FJ, Blangy A, Uze G (2005) Interferon-alpha and -beta differentially regulate osteoclastogenesis: role of differential induction of chemokine CXCL11 expression. Proc Natl Acad Sci USA 102(33):1191711922 doi:10.1073/pnas.0502188102

da Silva AJ, Brickelmaier M, Majeau GR, Lukashin AV, Peyman J, Whitty A et al (2002) Comparison of gene expression patterns induced by treatment of human umbilical vein endothelial cells with IFN-alpha $2 \mathrm{~b}$ vs. IFN-beta 1a: understanding the functional relationship between distinct type I interferons that act through a common receptor. J Interferon Cytokine Res 22(2):173-188. doi:10.1089/107999002753536149

Dhib-Jalbut S, Marks S (2010) Interferon-beta mechanisms of action in multiple sclerosis. Neurology 74(Suppl 1):S17-S24. doi:10.1212/WNL.0b013e3181c97d99

Dreser N, Zimmer B, Dietz C, Sugis E, Pallocca G, Nyffeler J et al (2015) Grouping of histone deacetylase inhibitors and other toxicants disturbing neural crest migration by transcriptional profiling. Neurotoxicology 50:56-70. doi:10.1016/j. neuro.2015.07.008

Ejlerskov P, Hultberg JG, Wang J, Carlsson R, Ambjorn M, Kuss $M$ et al (2015) Lack of neuronal IFN-beta-IFNAR causes lewy body- and Parkinson's disease-like dementia. Cell 163(2):324339. doi:10.1016/j.cell.2015.08.069

Falsig J, Porzgen P, Lotharius J, Leist M (2004) Specific modulation of astrocyte inflammation by inhibition of mixed lineage kinases with CEP-1347. J Immunol 173(4):2762-2770

FDA (1999) http://www.fda.gov/downloads/Drugs/DevelopmentApprovalProcess/HowDrugsareDevelopedandApproved/ApprovalApplications/TherapeuticBiologicApplications/ucm106138.pdf

Floris S, Ruuls SR, Wierinckx A, van der Pol SM, Dopp E, van der Meide PH et al (2002) Interferon-beta directly influences monocyte infiltration into the central nervous system. J Neuroimmunol 127(1-2):69-79

Fritsche E, Cline JE, Nguyen NH, Scanlan TS, Abel J (2005) Polychlorinated biphenyls disturb differentiation of normal human neural progenitor cells: clue for involvement of thyroid hormone receptors. Environ Health Perspect 113(7):871-876

Fuller LC, Cornelius SK, Murphy CW, Wiens DJ (2002) Neural crest cell motility in valproic acid. Reprod Toxicol 16(6):825-839

Grumbach IM, Fish EN, Uddin S, Majchrzak B, Colamonici OR, Figulla HR et al (1999) Activation of the Jak-Stat pathway in cells that exhibit selective sensitivity to the antiviral effects of IFN-beta compared with IFN-alpha. J Interferon Cytokine Res 19(7):797-801. doi:10.1089/107999099313659

Harbron C, Chang KM, South MC (2007) RefPlus: an R package extending the RMA Algorithm. Bioinformatics 23(18):24932494. doi:10.1093/bioinformatics/btm357
Harrill JA, Robinette BL, Mundy WR (2011) Use of high content image analysis to detect chemical-induced changes in synaptogenesis in vitro. Toxicol In Vitro 25(1):368-387. doi:10.1016/j. tiv.2010.10.011

Heim A, Stille-Seigener M, Pring-Akerblom P, Grumbach I, Brehm C, Kreuzer H et al (1996) Recombinant Interferons beta and gamma have a higher antiviral activity than interferon-alpha in coxsackievirus B3-infected carrier state cultures of human myocardial fibroblasts. J Interferon Cytokine Res 16(4):283-287. doi:10.1089/jir.1996.16.283

Henn A, Kirner S, Leist M (2011) TLR2 hypersensitivity of astrocytes as functional consequence of previous inflammatory episodes. J Immunol 186(5):3237-3247. doi:10.4049/jimmunol.1002787

Huang X, Saint-Jeannet JP (2004) Induction of the neural crest and the opportunities of life on the edge. Dev Biol 275(1):1-11. doi:10.1016/j.ydbio.2004.07.033

Josephson R, Sykes G, Liu Y, Ording C, Xu W, Zeng X et al. (2006) A molecular scheme for improved characterization of human embryonic stem cell lines. BMC Biol 4(28) doi:10.1186/1741-7007-4-28

Kleiderman S, Sá JV, Teixeira AP, Brito C, Gutbier S, Evje LG et al (2016) Functional and phenotypic differences of pure populations of stem cell-derived astrocytes and neuronal precursor cells. Glia 64(5):695-715. doi:10.1002/glia.22954

Krug AK, Balmer NV, Matt F, Schonenberger F, Merhof D, Leist M (2013a) Evaluation of a human neurite growth assay as specific screen for developmental neurotoxicants. Arch Toxicol 87(12):2215-2231. doi:10.1007/s00204-013-1072-y

Krug AK, Kolde R, Gaspar JA, Rempel E, Balmer NV, Meganathan $\mathrm{K}$ et al (2013b) Human embryonic stem cell-derived test systems for developmental neurotoxicity: a transcriptomics approach. Arch Toxicol 87(1):123-143. doi:10.1007/s00204-012-0967-3

Lee G, Papapetrou EP, Kim H, Chambers SM, Tomishima MJ, Fasano CA et al (2009) Modelling pathogenesis and treatment of familial dysautonomia using patient-specific iPSCs. Nature 461(7262):402-406. doi:10.1038/nature08320

Leist M, Hasiwa N, Rovida C, Daneshian M, Basketter D, Kimber I et al (2014) Consensus report on the future of animal-free systemic toxicity testing. ALTEX 31(3):341-356. doi:10.14573/ altex.1406091

Livak KJ, Schmittgen TD (2001) Analysis of relative gene expression data using real-time quantitative PCR and the 2(-Delta Delta C(T)) method. Methods 25(4):402-408. doi:10.1006/ meth.2001.1262

Lou J, Gasche Y, Zheng L, Giroud C, Morel P, Clements J et al (1999) Interferon-beta inhibits activated leukocyte migration through human brain microvascular endothelial cell monolayer. Lab Invest 79(8): 1015-1025

Lu E, Wang BW, Guimond C, Synnes A, Sadovnick D, Tremlett H (2012) Disease-modifying drugs for multiple sclerosis in pregnancy: a systematic review. Neurology 79(11):1130-1135. doi:10.1212/WNL.0b013e3182698c64

Menegola E, Broccia ML, Di Renzo F, Prati M, Giavini E (2000) In vitro teratogenic potential of two antifungal triazoles: triadimefon and triadimenol. In Vitro Cell Dev Biol Anim 36(2):88-95. doi:10.1290/1071-2690(2000)036<0088:IVTPOT $>2.0 . \mathrm{CO} ; 2$

Moraga I, Harari D, Schreiber G, Uze G, Pellegrini S (2009) Receptor density is key to the alpha2/beta interferon differential activities. Mol Cell Biol 29(17):4778-4787. doi:10.1128/MCB.01808-08

Nyffeler J, Karreman C, Leisner H, Kim YJ, Lee G, Waldmann T et al (2016) Design of a high-throughput human neural crest cell migration assay to indicate potential developmental toxicants. ALTEX. doi:10.14573/altex.1605031

Pallocca G, Grinberg M, Henry M, Frickey T, Hengstler JG, Waldmann $\mathrm{T}$ et al (2016) Identification of transcriptome signatures 
and biomarkers specific for potential developmental toxicants inhibiting human neural crest cell migration. Arch Toxicol 90(1):159-180. doi:10.1007/s00204-015-1658-7

Piehler J, Thomas C, Garcia KC, Schreiber G (2012) Structural and dynamic determinants of type I interferon receptor assembly and their functional interpretation. Immunol Rev 250(1):317-334. doi:10.1111/imr.12001

Pozzilli C, Pugliatti M (2015) An overview of pregnancy-related issues in patients with multiple sclerosis. Eur J Neurol 22(Suppl 2):34-39. doi:10.1111/ene.12797

Prat A, Parker JS, Karginova O, Fan C, Livasy C, Herschkowitz JI et al (2010) Phenotypic and molecular characterization of the claudin-low intrinsic subtype of breast cancer. Breast Cancer Res 12(5):R68. doi:10.1186/bcr2635

Rossi UA, Finocchiaro LM, Glikin GC (2015) Interferon-beta gene transfer inhibits melanoma cells adhesion and migration. Cytokine. doi:10.1016/j.cyto.2015.11.012

Sandberg-Wollheim M, Frank D, Goodwin TM, Giesser B, LopezBresnahan M, Stam-Moraga M, et al. (2005) Pregnancy outcomes during treatment with interferon beta-1a in patients with multiple sclerosis. Neurology 27(65(6)):802-806

Schindelin J, Arganda-Carreras I, Frise E, Kaynig V, Longair M, Pietzsch T et al (2012) Fiji: an open-source platform for biological-image analysis. Nat Methods 9(7):676-682. doi:10.1038/ nmeth.2019

Schmidt BZ, Lehmann M, Gutbier S, Nembo E, Noel S, Smirnova $L$ et al (2016) In vitro acute and developmental neurotoxicity screening: an overview of cellular platforms and highthroughput technical possibilities. Arch Toxicol. doi:10.1007/ s00204-016-1805-9

Schreiber G, Piehler J (2015) The molecular basis for functional plasticity in type I interferon signaling. Trends Immunol 36(3):139149. doi:10.1016/j.it.2015.01.002

Schroder K, Hertzog PJ, Ravasi T, Hume DA (2004) Interferongamma: an overview of signals, mechanisms and functions. J Leukoc Biol 75(2):163-189. doi:10.1189/jlb.0603252

Simões-Costa M, Bronner ME (2013) Insights into neural crest development and evolution from genomic analysis. Genome Res 23(7):1069-1080. doi:10.1101/gr.157586.113

Smirnova L, Hogberg HT, Leist M, Hartung T (2014) Developmental neurotoxicity - challenges in the 21 st century and in vitro opportunities. ALTEX 31(2):129-156. doi:10.14573/altex.1403271

Smyth GK, Michaud J, Scott HS (2005) Use of within-array replicate spots for assessing differential expression in microarray experiments. Bioinformatics 21(9):2067-2075. doi:10.1093/ bioinformatics/bti270

Staun-Ram E, Miller A (2011) Cathepsins (S and B) and their inhibitor Cystatin $\mathrm{C}$ in immune cells: modulation by interferon-beta and role played in cell migration. J Neuroimmunol 232(12):200-206. doi:10.1016/j.jneuroim.2010.10.015

Stiegler NV, Krug AK, Matt F, Leist M (2011) Assessment of chemical-induced impairment of human neurite outgrowth by multiparametric live cell imaging in high-density cultures. Toxicol Sci 121(1):73-87. doi:10.1093/toxsci/kfr034

Stuve O, Chabot S, Jung SS, Williams G, Yong VW (1997) Chemokine-enhanced migration of human peripheral blood mononuclear cells is antagonized by interferon beta- $1 \mathrm{~b}$ through an effect on matrix metalloproteinase-9. J Neuroimmunol $80(1-2): 38-46$
Tarassishin L, Lee SC (2013) Interferon regulatory factor 3 alters glioma inflammatory and invasive properties. J Neurooncol 113(2):185-194. doi:10.1007/s11060-013-1109-3

van Boxel-Dezaire AH, Rani MR, Stark GR (2006) Complex modulation of cell type-specific signaling in response to type I interferons. Immunity 25(3):361-372. doi:10.1016/j. immuni.2006.08.014

Waldmann T, Rempel E, Balmer NV, Konig A, Kolde R, Gaspar JA et al (2014) Design principles of concentration-dependent transcriptome deviations in drug-exposed differentiating stem cells. Chem Res Toxicol 27(3):408-420. doi:10.1021/tx400402j

Weng MK, Zimmer B, Pöltl D, Broeg MP, Ivanova V, Gaspar JA et al. (2012) Extensive transcriptional regulation of chromatin modifiers during human neurodevelopment. 7(5): e36708. doi:10.1371/ journal.pone.0036708

Weng MK, Natarajan K, Scholz D, Ivanova VN, Sachinidis A, Hengstler JG, et al. (2014) Lineage-specific regulation of epigenetic modifier genes in human liver and brain. 23;9(7): e102035. doi:10.1371/journal.pone.0102035

Yen JH, Kong W, Ganea D (2010) IFN-beta inhibits dendritic cell migration through STAT-1-mediated transcriptional suppression of CCR7 and matrix metalloproteinase 9. J Immunol 184(7):3478-3486. doi:10.4049/jimmunol.0902542

Yu F, Ng SS, Chow BK, Sze J, Lu G, Poon WS et al (2011) Knockdown of interferon-induced transmembrane protein 1 (IFITM1) inhibits proliferation, migration, and invasion of glioma cells. J Neurooncol 103(2):187-195. doi:10.1007/s11060-010-0377-4

Zimmer B, Kuegler PB, Baudis B, Genewsky A, Tanavde V, Koh W et al (2011a) Coordinated waves of gene expression during neuronal differentiation of embryonic stem cells as basis for novel approaches to developmental neurotoxicity testing. Cell Death Differ 18(3):383-395. doi:10.1038/cdd.2010.109

Zimmer B, Schildknecht S, Kuegler PB, Tanavde V, Kadereit S, Leist M (2011b) Sensitivity of dopaminergic neuron differentiation from stem cells to chronic low-dose methylmercury exposure. Toxicol Sci 121(2):357-367. doi:10.1093/toxsci/kfr054

Zimmer B, Lee G, Balmer NV, Meganathan K, Sachinidis A, Studer L et al (2012) Evaluation of developmental toxicants and signaling pathways in a functional test based on the migration of human neural crest cells. Environ Health Perspect 120(8):1116-1122. doi:10.1289/ehp.1104489

Zimmer B, Pallocca G, Dreser N, Foerster S, Waldmann T, Westerhout $\mathrm{J}$ et al (2014) Profiling of drugs and environmental chemicals for functional impairment of neural crest migration in a novel stem cell-based test battery. Arch Toxicol 88(5):11091126. doi:10.1007/s00204-014-1231-9

Zula JA, Green HC, Ransohoff RM, Rudick RA, Stark GR, van BoxelDezaire AH (2011) The role of cell type-specific responses in IFN-beta therapy of multiple sclerosis. Proc Natl Acad Sci USA 108(49):19689-19694. doi:10.1073/pnas.1117347108

Zurich MG, Honegger P, Schilter B, Costa LG, Monnet-Tschudi F (2000) Use of aggregating brain cell cultures to study developmental effects of organophosphorus insecticides. Neurotoxicology 21(4):599-605

Zurich MG, Eskes C, Honegger P, Berode M, Monnet-Tschudi F (2002) Maturation-dependent neurotoxicity of lead acetate in vitro: implication of glial reactions. J Neurosci Res 70(1):108116. doi:10.1002/jnr.10367 